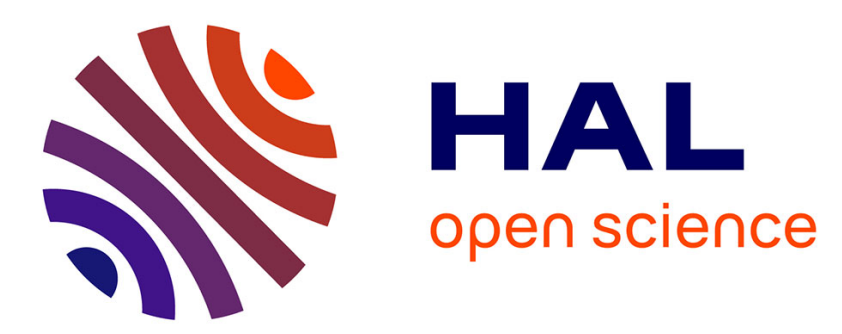

\title{
What induced the exceptional 2005 convection event in the northwestern Mediterranean basin? Answers from a modeling study.
}

Marine Herrmann, Jonathan Beuvier, Florence Sevault, Samuel Somot

\section{- To cite this version:}

Marine Herrmann, Jonathan Beuvier, Florence Sevault, Samuel Somot. What induced the exceptional 2005 convection event in the northwestern Mediterranean basin? Answers from a modeling study.. Journal of Geophysical Research. Oceans, 2010, 115 (C12051), pp.19. 10.1029/2010JC006162 . insu00562572

\section{HAL Id: insu-00562572 \\ https://hal-insu.archives-ouvertes.fr/insu-00562572}

Submitted on 3 Feb 2011

HAL is a multi-disciplinary open access archive for the deposit and dissemination of scientific research documents, whether they are published or not. The documents may come from teaching and research institutions in France or abroad, or from public or private research centers.
L'archive ouverte pluridisciplinaire HAL, est destinée au dépôt et à la diffusion de documents scientifiques de niveau recherche, publiés ou non, émanant des établissements d'enseignement et de recherche français ou étrangers, des laboratoires publics ou privés. 


\title{
1 What induced the exceptional 2005 convection event 2 in the northwestern Mediterranean basin? 3 Answers from a modeling study
}

\author{
4 Marine Herrmann, ${ }^{1}$ Florence Sevault, ${ }^{1}$ Jonathan Beuvier, ${ }^{1,2}$ and Samuel Somot ${ }^{1}$

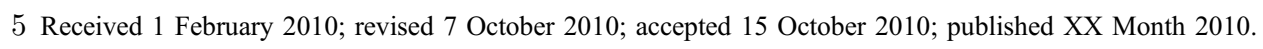 \\ 6 [1] Open-sea convection occurring in the northwestern Mediterranean basin (NWMED) is \\ 7 at the origin of the formation of Western Mediterranean Deep Water (WMDW), one of \\ 8 the main Mediterranean water masses. During winter 2004-2005, a spectacular convection \\ 9 event occurred, observed by several experimental oceanographers. It was associated \\ 10 with an exceptionally large convection area and unusually warm and salty WMDW. \\ 11 Explanations were proposed tentatively, relating the unusual characteristics of this event \\ 12 to the Eastern Mediterranean Transient (EMT) or to the atmospheric conditions during \\ 13 winter 2004-2005 in the NWMED. They could, however, not be supported until now. \\ 14 Here we used numerical modeling to understand what drove this convection event. \\ 15 The control simulation performed for the period 1961-2006 reproduces correctly the \\ 16 long-term evolution of the Mediterranean Sea circulation, the EMT, and the NWMED \\ 17 convection event of 2004-2005. Sensitivity simulations are then performed to assess \\ 18 the respective contributions of atmospheric and oceanic conditions to this event. The \\ 19 weakness of the winter buoyancy loss since 1988 in the NWMED prevented strong \\ 20 convection to occur during the 1990s, enabling heat and salt contents to increase in this \\ 21 region. This resulted in the change of WMDW characteristics observed in 2005. The \\ 22 strong buoyancy loss of winter 2004-2005 was responsible for the intensity of the \\ 23 convection observed this winter in terms of depth and volume of newly formed WMDW. \\ 24 The EMT did not fundamentally modify the convection process but potentially doubled \\ 25 this volume by inducing a deepening of the heat and salt maximum that weakened the \\ 26 preconvection stratification.
}

27 Citation: Herrmann, M., F. Sevault, J. Beuvier, and S. Somot (2010), What induced the exceptional 2005 convection event in 28 the northwestern Mediterranean basin? Answers from a modeling study, J. Geophys. Res., 115, XXXXXX,

29 doi:10.1029/2010JC006162.

\section{1. Introduction}

31 [2] Open-sea deep convection takes place in a few regions 32 of the world, among which the northwestern Mediterranean 33 basin (NWMED) [Marshall and Schott, 1999]. In this region, 34 strong winter surface buoyancy loss associated with northern 35 wind events (Mistral, Tramontane) induce deep convection 36 events, at the origin of the formation of Western Mediter37 ranean Deep Water (WMDW). During winter 2004-2005, an 38 exceptionally strong convection event was observed by 39 several experimental oceanographers [López-Jurado et al., 40 2005; Salat et al., 2006; Schröder et al., 2006; Font et al., 41 2007; Schroeder et al., 2008; Smith et al., 2008]: convection 42 reached the bottom and covered an area much larger than 43 usually, and WMDW formed this winter was significantly 44 saltier and warmer than the values reported in the literature 45 (Table 1). Two major explanations for the exceptional

${ }^{1}$ CNRM-GAME, Météo-France/CNRS, Toulouse, France.

${ }^{2}$ ENSTA-ParisTech/UME, Palaiseau, France.

Copyright 2010 by the American Geophysical Union. 0148-0227/10/2010JC006162 characteristics of this convection event (intensity and 46 WMDW characteristics) were proposed by those authors. 47

[3] First, winter 2004-2005 was one of the coldest and 48 driest winters of the last 40 years [López-Jurado et al., 49 2005; Font et al., 2007], thus associated with strong sur- 50 face heat, water and buoyancy losses. The formation of 51 dense water at the surface being triggered by the buoyancy 52 loss, those atmospheric conditions certainly played a role in 53 the intensity of the deep convection event. Moreover, the 54 strong water loss must have induced an increase of the 55 surface salinity which could partly explain the larger salinity 56 of WMDW formed this year.

57

[4] Second, López-Jurado et al. [2005] suggested that the 58 unusual characteristics of the 2005 convection event could 59 be due to an alteration of the water masses advected into the 60 convection area. Millot [2005] also proposed that some 61 observed changes in the Western Mediterranean Deep Water 62 masses could be due to the presence of modified eastern 63 waters brought to the Western basin after the Eastern 64 Mediterranean Transient (EMT, corresponding to the shift 65 of production of Eastern Mediterranean Deep Water from 66 the Adriatic to the Aegean subbasins at the beginning of the 67 
Table 1. Observed Characteristics of the Old WMDW (Formed Before 2005) and New WMDW (Formed in 2005) ${ }^{\mathrm{a}}$

\begin{tabular}{|c|c|c|c|c|c|c|c|}
\hline \multirow[b]{2}{*}{$\mathrm{t} 1.3$} & \multirow[b]{2}{*}{ Authors } & \multicolumn{3}{|c|}{ Old DW } & \multicolumn{3}{|c|}{ New DW } \\
\hline & & $T_{D W}\left({ }^{\circ} \mathrm{C}\right)$ & $S_{D W}$ & $\rho_{D W}\left(\mathrm{~kg} \mathrm{~m}^{-3}\right)$ & $T_{D W}\left({ }^{\circ} \mathrm{C}\right)$ & $S_{D W}$ & $\rho_{D W}\left(\mathrm{~kg} \mathrm{~m}^{-3}\right)$ \\
\hline $\mathrm{t} 1.4$ & Mertens and Schott [1998] & $12.75-12.92$ & $38.41-38.46$ & $29.09-29.10$ & & & \\
\hline $\mathrm{t} 1.5$ & López-Jurado et al. [2005] & $12.83-12.85$ & $38.44-38.46$ & & 12.88 & $38.48-38.49$ & \\
\hline $\mathrm{t} 1.6$ & Schröder et al. [2006] & $12.8-12.85$ & $38.44-38.46$ & & $12.87-12.90$ & $38.47-38.48$ & \\
\hline $\mathrm{t} 1.7$ & Salat et al. [2006] & $12.75-12.82$ & $38.43-38.47$ & $29.115-29.120$ & $12.87-12.90$ & $38.49-38.50$ & 29.130 \\
\hline $\mathrm{t} 1.8$ & Font et al. [2007] & $12.8-12.9$ & $38.43-38.46$ & 29.09-29.10 & 12.88 & 38.48 & 29.117 \\
\hline $\mathrm{t} 1.9$ & Smith et al. [2008] & 12.86 & 38.46 & 29.108 & 12.89 & 38.48 & 29.113 \\
\hline $\mathrm{t} 1.10$ & This study:CTRL, 2005 & $12.73-12.80$ & $38.423-38.44$ & $>29.10$ & 12.90 & 38.483 & 29.116 \\
\hline
\end{tabular}

t1.11 ${ }^{\mathrm{a}}$ The values obtained in CTRL from the temperature-salinity diagram shown in Figure 7a are also indicated, with old WMDW corresponding to water

t1.12 denser than $29.10 \mathrm{~kg} \mathrm{~m}^{-3}$ present in LION on 1 December 2004 and new WMDW corresponding to the densest water formed on $10 \mathrm{March} 2005 . T_{D W}$,

t1.13 temperature; $S_{D W}$, salinity; $\rho_{D W}$, density.

68 1990s; see Roether et al. [2007] for a detailed description of 69 the EMT). Gasparini et al. [2005] indeed showed that the 70 EMT induced an increase of the density of the eastern 71 waters flowing westward through the Sicily channel asso72 ciated with a remarkable injection of heat and salt in 73 the deep Tyrrhenian subbasin. Consequently, López-Jurado 74 et al. [2005], Schröder et al. [2006] and Schroeder et al. 75 [2008] suggested that the EMT induced the warming and 76 salting of the intermediate and deep layer of the NWMED. 77 Being mixed with the rest of the water column when deep 78 convection occurs, this layer participates in the composition 79 of WMDW. This could thus explain the warming and salting 80 of WMDW formed in 2005. Moreover, it could have 81 induced a modification of the water column structure, hence 82 of the stratification, which could have impacted the exten83 sion of the deep convection volume.

84 [5] Until now, those explanations were proposed tenta85 tively, but have not been supported yet. In particular, the 86 relative contributions of the atmospheric and oceanic con87 ditions to the characteristics of the 2005 deep convection 88 event still need to be clearly quantified. Observations were 89 indeed very useful to characterize this event, but they do not 90 provide sufficiently continuous spatial and temporal cover91 age to answer to those questions. Realistic numerical 92 modeling can help to apprehend the 4-D evolution of the sea 93 and therefore help to interpret and understand observations. 94 To our knowledge, however, no realistic oceanic simulation 95 of the NWMED circulation in 2004-2005 has been per96 formed until now: Herrmann et al. [2009] presented a 97 simulation that was carried out for the 1998-2007 period, 98 but it did not reproduced the change of WMDW char99 acteristics observed in 2005. In this context, our goal is to 100 perform realistic numerical modeling of the NWMED 2005 101 convection event but also of the long-term Mediterranean 102 circulation before 2004, in order to understand precisely 103 what triggered this event, and to quantify the contribution of 104 the different factors involved.

105 [6] We present the numerical model and the simulations 106 in section 2. Results are then presented and discussed in 107 section 3. We first examine the long-term evolution of the 108 water column until 2004 in the NWMED and the influence 109 of the EMT on the NWMED oceanic conditions. We then 110 show that the model is able to represent realistically the 111 2004-2005 NWMED convection event. Finally, we deter112 mine which factors were responsible for the exceptional 113 characteristics of this event. For that, we assess the influence 114 of the oceanic and atmospheric conditions before and during 115 winter 2004-2005. Conclusion and future works are pre- sented in section 4. Note that in the following, all the values 116 given for temperature and density correspond to potential 117 temperature and density.

\section{Tools and Methods}

\subsection{Numerical Model}

[7] We use the NEMOMED8 model, a Mediterranean 121 version of the NEMO numerical ocean model [Madec, 2008] 122 used and described by Beuvier et al. [2010] and Sevault et al. 123 [2009]. It is an updated version of the model used by Somot 124 et al. [2006] and Herrmann et al. [2008] to study the 125 NWMED deep convection. NEMOMED8 covers the whole 126 Mediterranean Sea plus a buffer zone including a part of the 127 near Atlantic Ocean (see Figure 1). The horizontal resolution 128 is $1 / 8^{\circ} \times 1 / 8^{\circ} \cos (\phi)$, with $\phi$ the latitude, equivalent to a range 129 of 9 to $12 \mathrm{~km}$ from the north to the south of the Mediterranean 130 domain. The grid is tilted and stretched at the Gibraltar Strait 131 in order to better follow the SW-NE axis of the real strait 132 and to increase the local resolution up to $6 \mathrm{~km}$. The Gibraltar 133 Strait is represented with a two-grid point wide strait. 134 NEMOMED8 has 43 vertical Z levels with an inhomoge- 135 neous distribution (from $Z=6 \mathrm{~m}$ at the surface to $Z=200 \mathrm{~m}$ at 136 the bottom with 25 levels in the first $1000 \mathrm{~m}$ ). The bathymetry 137 is based on the ETOPO 5' $\times 5^{\prime}$ database [Smith and Sandwell, 138 1997]. A time step of $20 \mathrm{~min}$ is applied. NEMOMED8 has a 139 filtered free-surface and partial-cell parametrization. The 140 horizontal eddy diffusivity is fixed to $125 \mathrm{~m}^{2} \mathrm{~s}^{-1}$ for the 141 tracers (temperature, salinity) using a Laplacian operator and 142 the horizontal viscosity coefficients is fixed to $-1.010^{10} \mathrm{~m}^{2} 143$ $\mathrm{s}^{-2}$ for the dynamics (velocity) using a biharmonic operator. 144 A 1.5 turbulent closure scheme is used for the vertical eddy 145 diffusivity [Blanke and Delecluse, 1993] with an enhance- 146 ment of the vertical diffusivity coefficient up to $50 \mathrm{~m}^{2} \mathrm{~s}^{-1}$ in 147 case of unstable stratification. A no-slip lateral boundary 148 condition is used and the bottom friction is quadratic. The 149 TVD (Total Variance Dissipation) scheme [Barnier et al., 150 2006] is used for the tracer advection. NEMOMED8 con- 151 serves energy and enstrophy. The solar radiation can pene- 152 trate into the ocean surface layers [Bozec et al., 2008]. 153

\subsection{Forcings}

154

2.2.1. Surface Boundary Conditions: Atmospheric 155 Forcing

[8] To prescribe air-sea fluxes to the ocean model, we use 157 the results of a high-resolution atmospheric data set named 158 ARPERA obtained by performing a dynamical downscaling 159 of ECMWF fields. Based on the study of the real case of 160 


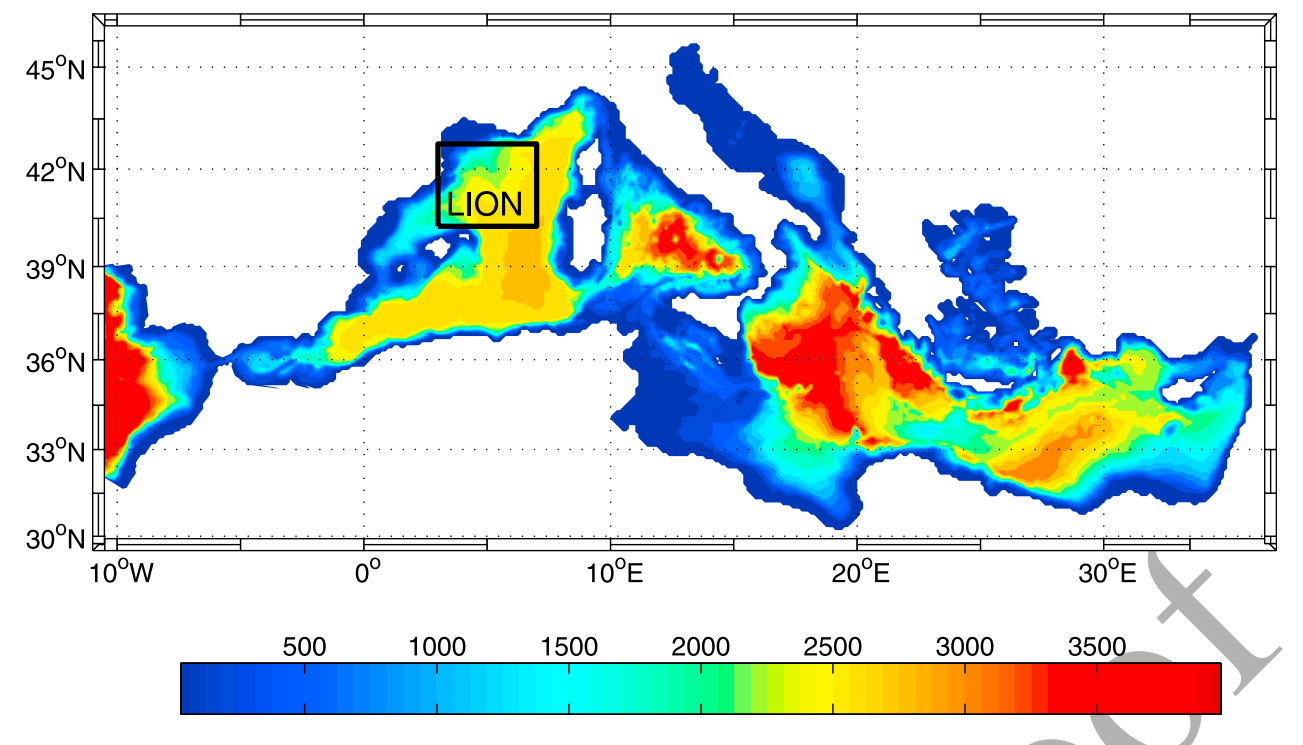

Figure 1. Bathymetry of the modeled domain. The black box corresponds to the LION area, from $3^{\circ} \mathrm{W}$ to $7^{\circ} \mathrm{W}$ and from $40.25^{\circ} \mathrm{N}$ to $42.75^{\circ} \mathrm{N}$. Unit is meters.

161 winter 1986-1987, Herrmann and Somot [2008] showed that 162 this data set followed very well the real atmospheric chro163 nology and was relevant to model realistically deep con164 vection in the NWMED. The downscaling method was 165 described in detail by Guldberg et al. [2005]. The principle is 166 to use a high-resolution atmospheric model, here ARPEGE167 Climate [Déqué and Piedelievre, 1995], in which small 168 scales can develop freely and large scales are driven by 169 ECMWF fields. The synoptic chronology then follows that 170 of ECMWF fields while the high-resolution structures of the 171 atmospheric flow are created by the model. For the period 172 1958-2001, fields of ERA40 reanalysis [Gibson et al., 1997] 173 are used to drive ARPEGE-Climate. Between 2002 and 174 2006, fields of ECMWF analysis are used, their resolution $175\left(0.5^{\circ} \sim 55 \mathrm{~km}\right)$ being downgraded down to ERA40 resolution $176\left(1.125^{\circ} \sim 125 \mathrm{~km}\right)$ in order to insure consistency between the 177 1958-2001 and 2002-2006 periods.

178 [9] The forcing fields for NEMOMED8 are the momen179 tum, freshwater and heat fluxes. A relaxation term toward 180 ERA40 sea surface temperature (SST) is applied for the heat 181 flux. This term actually plays the role of a first-order cou182 pling between the SST computed by the ocean model and 183 the atmospheric heat flux, ensuring the consistency between 184 those terms. Following CLIPPER Project Team [1999], the 185 relaxation coefficient is $-40 \mathrm{~W} \mathrm{~m}^{-2} \mathrm{~K}^{-1}$, equivalent to an 1868 day restoring time scale.

187 [10] The LION area (see Figure 1) is chosen in order to 188 cover entirely the region of NWMED deep convection 189 reported in the literature [Marshall and Schott, 1999]. 190 Figure 2 shows the evolution of the mean September191 November, December-February and September-February 192 surface heat, water and buoyancy losses over LION (HL, WL 193 and $B L$ ) between winters 1961-1962 and 2005-2006. The 194 following formula [Mertens and Schott, 1998] is used for BL:

$$
B L=g \cdot\left(\frac{\alpha \cdot H L}{\rho_{0} \cdot C_{p}}-\beta . S S S . W L\right)=B L_{H}+B L_{W}
$$

where $g=9.81 \mathrm{~m} \mathrm{~s}^{-2}$ is the gravitational acceleration, $\rho_{0}=195$ $1020 \mathrm{~kg} \mathrm{~m}^{-3}$ is the density reference, $C_{p}=4000 \mathrm{~J} \mathrm{~kg}^{-1} \mathrm{~K}^{-1}$ is 196 the specific heat of water, $\alpha=2.10^{-4} \mathrm{~K}^{-1}$ and $\beta=7.6 .10^{-4}$ are 197 the thermal and saline expansion coefficients and SSS is the 198 sea surface salinity. In agreement with what was previously 199 observed by López-Jurado et al. [2005] using NCEP [Kalnay 200 et al., 1996] and by Font et al. [2007] using the data of 201 the Portbou station from the Catalan Meteorological service, 202 the ARPERA data set shows that winter 2004-2005 was the 203 coldest and second driest winter of the 1961-2006 period, 204 hence the one with the strongest buoyancy loss (highest 205 values of $H L=265 \mathrm{~W} \mathrm{~m}^{-2}$ versus $147 \pm 47 \mathrm{~W} \mathrm{~m}^{-2}$ in average 206 over the 1961-2006 period, $W L=4.42 \mathrm{~mm} \mathrm{~d}^{-1}$ versus $2.96 \pm 207$ $0.79 \mathrm{~mm} \mathrm{~d}^{-1}$ and $B L=1.4210^{-7} \mathrm{~m}^{2} \mathrm{~s}^{-3}$ versus $0.80 \pm 0.24208$ $\left.10^{-7} \mathrm{~m}^{2} \mathrm{~s}^{-3}\right)$. This was due to the occurrence of several 209 intense atmospheric events associated with strong winds and 210 to cold and dry air masses, during which $H L$ and $W L$ exceeded 211 $500 \mathrm{~W} \mathrm{~m}^{-2}$ and $10 \mathrm{~mm} \mathrm{~d}^{-1}$, respectively. This is shown in 212 Figure $3 \mathrm{a}$ where we present the evolution of the daily average 213 over LION between December 2004 and April 2005 of HL, 214 $W L, B L$ and the wind velocity computed in ARPERA and of 215 the wind velocity given by QuikSCAT LEVEL 3 data set 216 [Perry, 2001] (available on http://podaac.jpl.nasa.gov:2031/ 217 DATASET_DOCSqscat_13.html). Events of strong buoy- 218 ancy loss are highlighted in gray in Figure 3. As already 219 shown by Herrmann and Somot [2008] for winter 1986- 220 1987, ARPERA follows very well the real atmospheric 221 chronology for winter 2004-2005: the modeled wind velocity 222 is correlated with the observed wind velocity obtained from 223 QuikSCAT with a correlation factor of 0.970 (significant level 224 $>0.999$ ). The wind intensity is also correctly reproduced: 225 the mean value over LION between December 2004 and 226 March 2005 is equal to $8.32 \mathrm{~m} \mathrm{~s}^{-1}$ in ARPERA versus $9.12 \mathrm{~m} 227$ $\mathrm{s}^{-1}$ in QuikSCAT, with a RMSE of $1.67 \mathrm{~m} \mathrm{~s}^{-1}$. 228 2.2.2. Lateral Boundary Conditions: River, Black Sea 229 and Atlantic Forcings

[11] No salinity damping is used at the surface and a 231 freshwater flux due to rivers runoff is explicitly added to 232 

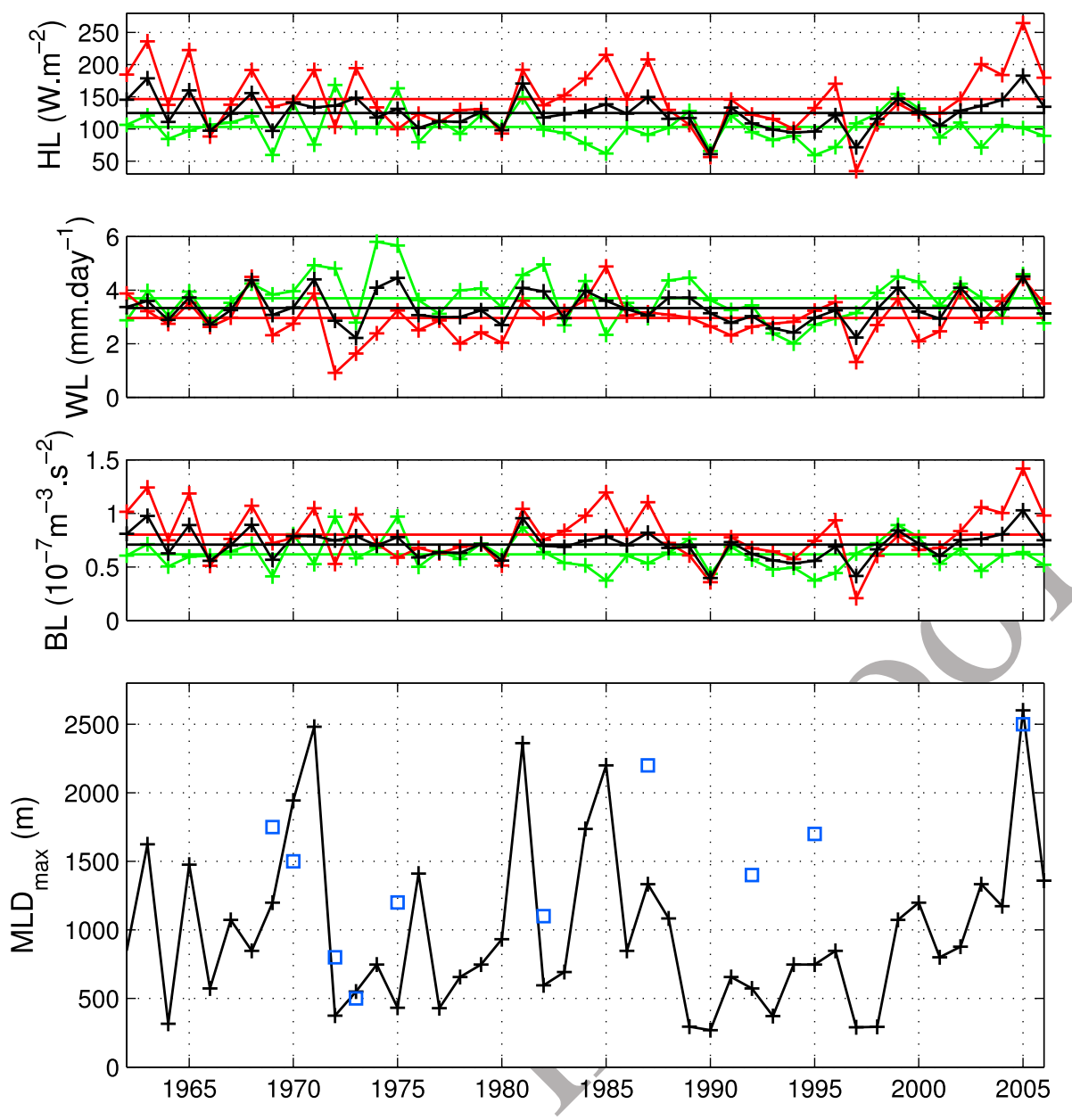

Figure 2. Atmospheric forcing and deep convection: time series of the average autumn (SeptemberNovember, green), winter (December-February, red), and autumn plus winter (September-February, black) surface heat loss $(H L)$, water loss $(W L)$, and buoyancy loss $(B L)$ over LION in ARPERA and of the winter maximum of the spatial maximum of $M L D$ over LION $\left(M L D_{\max }\right)$ between winter 19611962 and winter 2005-2006. Here 1965 corresponds to winter 1964-1965. For the atmospheric fluxes the horizontal lines indicate the mean values over 1961-2005. Blue squares correspond to observed MLD values available through several oceanographic cruises and reported by Mertens and Schott [1998], Testor and Gascard [2006], and Schröder et al. [2006].

233 complete the surface water budget. Here we use a monthly 234 mean climatology (constant over the years) computed from 235 the RivDis database [Vörösmarty et al., 1996] for the main 23633 rivers of the Mediterranean Sea catchment basin.

237 [12] The Black Sea, not included in NEMOMED8, is one 238 of the major freshwater sources for the Mediterranean Sea. 239 The exchanges between the Black Sea and the Aegean 240 subbasin consist of a two-layer flow across the Marmara Sea 241 and the Dardanelles Strait. We assume that this flow can be 242 approximated by a freshwater flux diluting the salinity of the 243 mouth grid point. Thus, the Black Sea is considered as a river for the Aegean. We use a monthly mean climatology 244 for this net flux based on the data collected by Stanev et al. 245 [2000].

[13] The exchanges with the Atlantic Ocean are performed 247 through a buffer zone from $11^{\circ} \mathrm{W}$ to $7.5^{\circ} \mathrm{W}$. Temperature 248 and salinity in this area are relaxed toward the 3-D T-S 249 fields of the seasonal Reynaud et al. [1998] climatology by 250 means of a Newtonian damping term in the tracer equation 251 equal to $-\left(X_{\text {model }}-X_{\text {climatology }}\right) / \tau$. The restoring term is weak 252 close to the Gibraltar Strait $\left(\tau=100\right.$ days at $\left.7.5^{\circ} \mathrm{W}\right)$ and 253 stronger moving away from it $\left(\tau=3\right.$ days at $\left.11^{\circ} \mathrm{W}\right)$.

Figure 3. (a) Time series during winter 2004-2005 of the average over LION of the daily wind velocity in ARPERA (black) and QuikSCAT (gray) and of the surface heat, water, and buoyancy losses $(H L, W L, B L)$ in ARPERA. For the buoyancy loss, the thin black (gray) line corresponds to the contribution of the water loss $\left(B L_{W}\right)$ (heat loss $\left(B L_{H}\right)$ ), and the thick line corresponds to the total $B L\left(=B L_{H}+B L_{W}\right)$. (b) Time series of the maximum MLD over LION, $M L D_{\max }$, and of the volume of WMDW formed during winter 2004-2005, $V_{D W}$, for each simulation performed under the atmospheric forcing of 2004-2005 (CIXX and year 2004-2005 of CTRL and NEMT). 
(a)
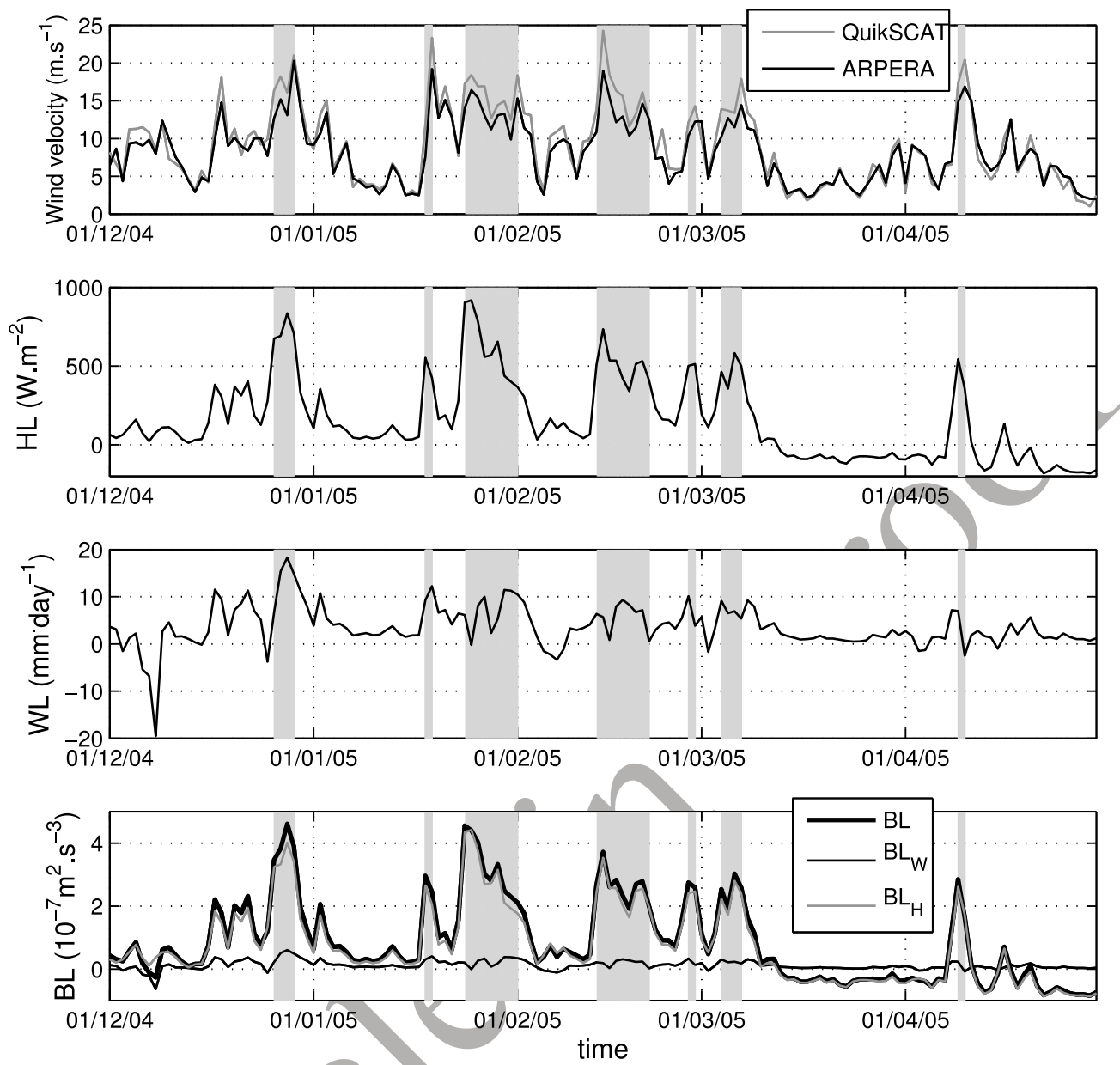

(b)
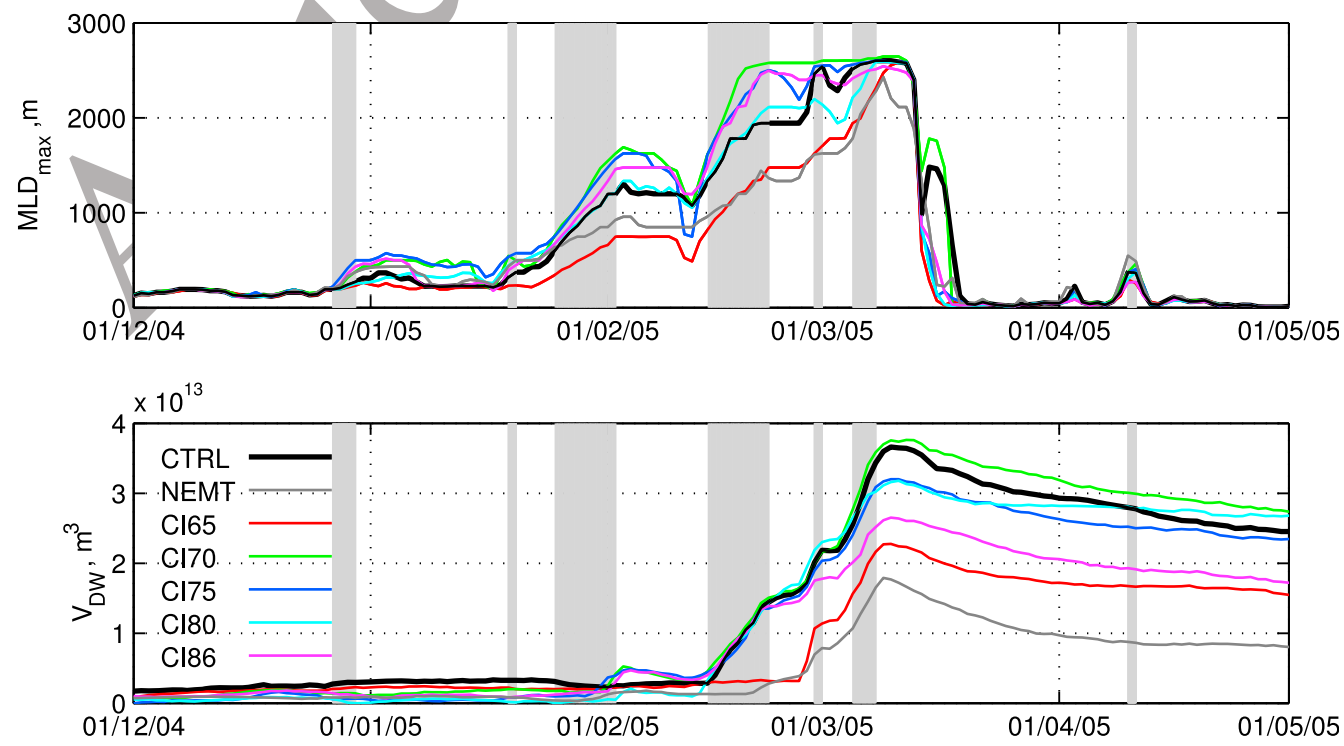

Figure 3 

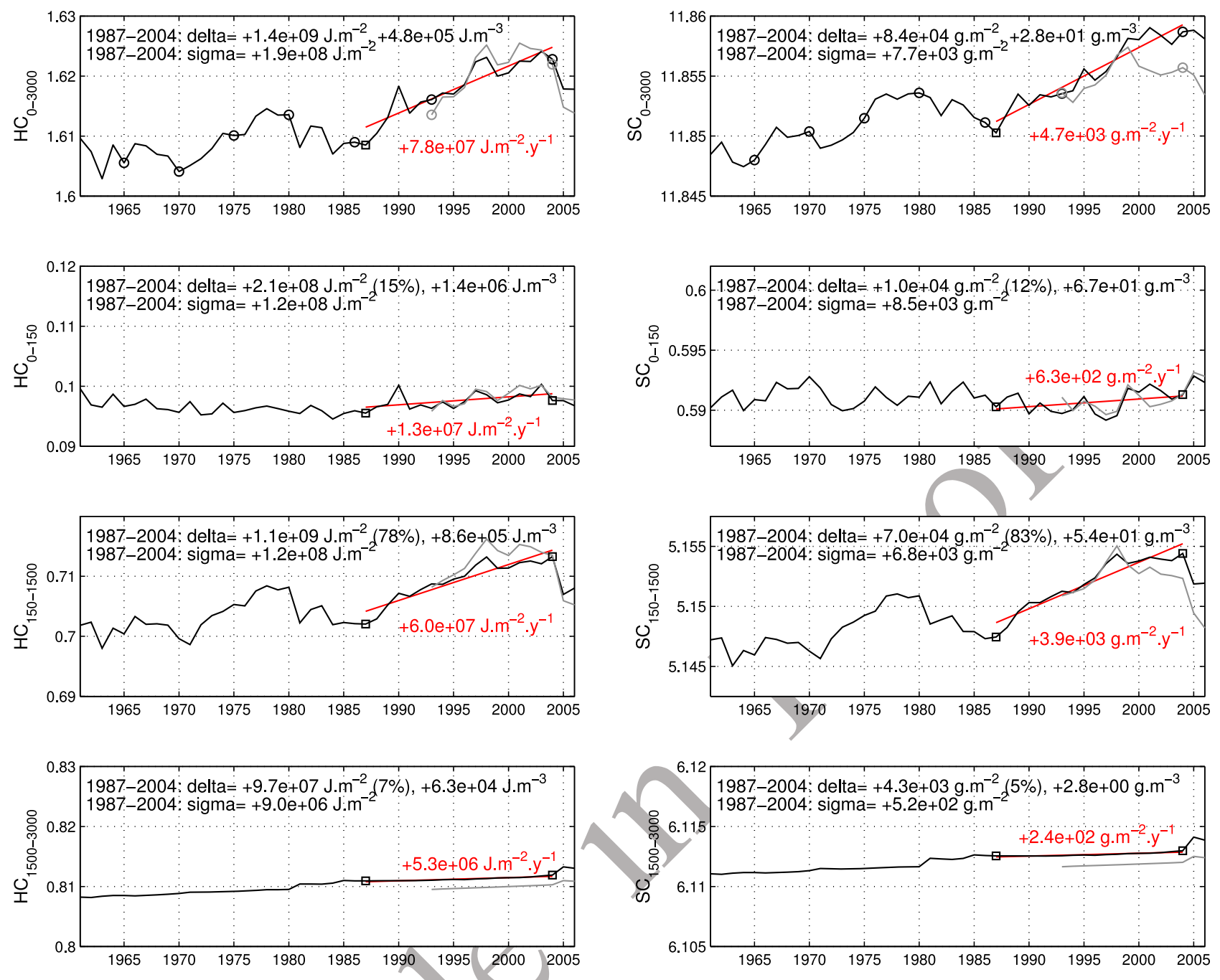

Figure 4. Time series of the mean August (left) heat $\left(H C, 10^{11} \mathrm{~J} \mathrm{~m}^{-2}\right)$ and (right) salt $\left(S C, 10^{7} \mathrm{~g} \mathrm{~m}^{-2}\right)$ contents of the average water column over LION between 1961 and 2006 in CTRL (black) and between 1993 and 2006 in NEMT (gray) for the whole water column (top line) and the layers 0-150 m (second line), $150-1500 \mathrm{~m}$ (third line), and $1500 \mathrm{~m}$ to bottom (bottom line). The red line shows the trend between 1987 and 2004 in CTRL, obtained from a linear regression analysis. The value of the trend is indicated in red. Delta indicates the variation of those contents between August 1987 and August 2004 in CTRL, the contribution of each sublayer to the total variation, and the variation of the volumic contents. Sigma is the standard deviation of the time series between 1987 and 2004 in CTRL after the trend has been removed. Circles indicate the years selected to perform the sensitivity simulation CIXX. Squares indicate years 1987 and 2004.

\section{2.3. Simulations}

256 [14] To answer to the scientific questions posed in section 1 , 257 we performed several numerical simulations.

\section{2.3.1. Control Simulation CTRL}

259 [15] Beuvier et al. [2010] performed an oceanic simula260 tion of the Mediterranean circulation for the 1960-2000 261 period with NEMOMED8, using the forcings presented 262 above for the surface and lateral boundary conditions (run 263 NM8-ctrl in their paper). The details of this simulation 264 (initial conditions, spin-up) are given in their paper. The 265 initial conditions are given by the MEDATLAS-II clima266 tology [MEDAR/MEDATLAS Group, 2002] for the Medi267 terranean part of the model, and by the Reynaud et al. 268 [1998] climatology for the Atlantic buffer zone. A 15 year spin-up was then performed before to launch the simulation 269 in August 1960. Beuvier et al. [2010] showed that the EMT 270 was realistically reproduced in this simulation: due to an 271 accumulation of dense water in the Aegean during the 1980s 272 and beginning of the 1990s, plus a strong buoyancy loss 273 over the Aegean during winters 1991-1992 and 1992-1993, 274 very dense water $\left(\rho>29.2 \mathrm{~kg} \mathrm{~m}^{-3}\right)$ filled $75 \%$ of the Aegean 275 in 1993. This water then cascaded through the Cretan Arc 276 sills into the Ionian and Levantine subbasins and propagated 277 through the rest of the Eastern basin. They also validated the 278 evolution over the period 1960-2000 of the heat and salt 279 contents of the different layers of the Mediterranean Sea, 280 by comparing them to the interannual values given by Rixen 281 et al. [2005]. 
Table 2. Simulations Used in This Study: Name of the Simulation, Atmospheric Forcing Used During the Simulation, and Oceanic Conditions at the Beginning of the Simulation

\begin{tabular}{lcc}
\hline Name & Atmospheric Forcing: ARPERA & Initial Oceanic Conditions \\
\hline CTRL & Aug 1960 to Aug 2005 & After the initial spin-up: \\
& & Aug 1960 \\
CI65 & Aug 2004 to Aug 2005 & Aug 1965 of CTRL \\
CI70 & Aug 2004 to Aug 2005 & Aug 1970 of CTRL \\
CI75 & Aug 2004 to Aug 2005 & Aug 1975 of CTRL \\
CI80 & Aug 2004 to Aug 2005 & Aug 1980 of CTRL \\
CI86 & Aug 2004 to Aug 2005 & Aug 1986 of CTRL \\
AF65 & Aug 1965 to Aug 1966 & Aug 2004 of CTRL \\
AF70 & Aug 1970 to Aug 1971 & Aug 2004 of CTRL \\
AF75 & Aug 1975 to Aug 1976 & Aug 2004 of CTRL \\
AF80 & Aug 1980 to Aug 1981 & Aug 2004 of CTRL \\
AF86 & Aug 1986 to Aug 1987 & Aug 2004 of CTRL \\
NEMT & Aug 1993 to Aug 2005 & Aug 1980 of CTRL \\
\hline
\end{tabular}

283 [16] For this study, we extended this simulation until 284 2006, still using the same forcings (ARPERA for the 285 atmospheric fluxes, Vörösmarty et al. [1996] for the rivers, 286 Stanev et al. [2000] for the Black Sea and Reynaud et al. 287 [1998] for the Atlantic Ocean). In the following, this sim288 ulation is named CTRL.

289 2.3.2. Sensitivity Simulations

290 2.3.2.1. Impact of the Oceanic Conditions on the Deep 291 Convection Event: Simulations CIXX

292 [17] To investigate the influence of oceanic conditions on 293 the convection event, we performed a first group of sensi294 tivity simulations varying the oceanic conditions before the 295 beginning of the convection event, i.e., in August 2004. For 296 that, we selected contrasted initial oceanic conditions from 297 the CTRL simulation: we considered the mean August heat 298 and salt contents over the whole water column in LION 299 (Figure 4) and selected five contrasted oceanic conditions 300 before the beginning of the EMT, i.e., before 1987: 1965, 301 1970, 1975, 1980 and 1986. The heat and salt contents over 302 LION, $H C$ (unit: $\mathrm{J} \mathrm{m}^{-2}$ ) and $S C$ (unit: $\mathrm{g} \mathrm{m}^{-2}$ ), are computed 303 using the following formula:

$$
\begin{aligned}
& H C=\frac{1}{A_{L I O N}} \times \iiint_{\text {LION }} c_{p} \rho(x, y, z) T(x, y, z) d x d y d z \\
& S C=\frac{1}{A_{L I O N}} \times \iiint_{\text {LION }} \rho(x, y, z) S(x, y, z) d x d y d z
\end{aligned}
$$

304 where $A_{L I O N}=9.4010^{10} \mathrm{~m}^{2}$ is the surface of the LION area. 305 The division by $A_{L I O N}$ is done in order to obtain an average 306 surfacic value for a column of $1 \mathrm{~m}^{2}$ of the LION area, so that 307 we will be able to compare it with the surface and lateral 308 fluxes in the following. Five simulations were then launched 309 in August 2004 using those oceanic conditions as initial 310 conditions, and the same atmospheric conditions as CTRL, 311 i.e., ARPERA from August 2004. Those simulations are 312 named CI65, CI70, CI75, CI80 and CI86 in the following. 313 2.3.2.2. Impact of the Atmospheric Conditions on the 314 Deep Convection Event: Simulations AF $\boldsymbol{X} \boldsymbol{X}$

315 [18] We performed a second group of sensitivity simula316 tions in order to investigate the influence of atmospheric 317 forcing during the convection event: we ran five simulations 318 from August to May taking the same initial oceanic condi319 tions, those of August 2004 of CTRL, but varying the 320 atmospheric forcing. For that we took the atmospheric forcing of August 1965 to May 1966, August 1970 to May 321 1971, August 1975 to May 1976, August 1980 to May 1981322 and August 1986 to May 1987 from ARPERA. Those 323 simulations are named AF65, AF70, AF75, AF80 and AF86 324 in the following.

2.3.2.3. Impact of the EMT on the 2005 Convection 326 Event: Simulation NEMT 327

[19] One of our main objectives is to determine the impact 328 of the EMT on the NWMED convection event of 2004- 329 2005. For that, we performed an additional simulation 330 beginning in August 1993, i.e., just after the EMT, but with 331 the oceanic conditions of August 1980, which are close to 332 August 1993 from the point of view of the heat and salt 333 contents (see Figure 4). This simulation is called NEMT. It 334 cannot contain the EMT signal that occurred between 1987335 and 1993, but it is influenced by the same long-term (1993- 336 2004) external forcings as CTRL (surface, hydrologic and 337 lateral boundary conditions). The differences between 338 NEMT and CTRL can therefore be mainly attributed to the 339 impact of the EMT.

[20] The characteristics of the simulations performed for 341 this study are summarized in the first three columns of Table 342 2: name of the simulation, atmospheric forcing and initial 343 oceanic conditions.

\section{Results}

3.1. Characteristics of the NWMED Water Column Between 1960 and 2004: Long-Term Evolution and Influence of the EMT

[21] In this section we examine the factors responsible for 349 the evolution until autumn 2004 of the oceanic conditions in 350 the NWMED in terms of heat and salt contents and structure 351 of the water column. 352 3.1.1. Evolution of the Heat and Salt Contents 353

[22] Schroeder et al. [2010] observed that the salt and heat 354 contents of the water column in the NWMED were anom- 355 alously high in 2004. This is reproduced in the CTRL 356 simulation: between August 1987 and August 1998, the heat 357 and salt contents in LION increase regularly, then remain 358 relatively stable until August 2004 (Figure 4). As a result, 359 between 2000 and 2004, these contents are the highest of the 360 whole 1960-2005 period. Between 1987 and 2004, the 361 variation of heat and salt contents are equal to $1.410^{9} \mathrm{~J} \mathrm{~m}^{-2} 362$ and $8.410^{4} \mathrm{~g} \mathrm{~m}^{-2}$, respectively. Performing a linear 363 regression analysis, we compute trends of those contents 364 between 1987 and 2004 of $+7.810^{7} \mathrm{~J} \mathrm{~m}^{-2} \mathrm{yr}^{-1}$ and +4.7365 $10^{3} \mathrm{~g} \mathrm{~m}^{-2} \mathrm{yr}^{-1}$, respectively. The standard deviations of the 366 detrended signals are equal to $1.910^{8} \mathrm{~J} \mathrm{~m}^{-2}$ and $7.710^{3} \mathrm{~g} 367$ $\mathrm{m}^{-2}$, respectively: those values are 1 order smaller than the 368 values of the variation between 1987 and 2004. The increase 369 observed during this period is therefore statistically signifi- 370 cant and not simply due to the interannual variability. 371

[23] Schroeder et al. [2008] suggested that these anoma- 372 lously high contents could be partly due to an anomalously 373 high arrival of heat and salt from the Eastern basin. How- 374 ever, the regularity of this increase in the model suggests 375 that it is not the case. Moreover, the evolution of the heat 376 and salt contents is very similar in NEMT (Figure 4), which, 377 by construction, does not contain any signal due to the EMT 378 contrary to CTRL. This shows that this increase of heat and 379 salt contents, whatever its origin, was not related to the 380 
381 EMT. Note that on 1 December 2004, the heat contents are 382 quasi equal in NEMT and CTRL, but that the salt content is 383 slightly higher in CTRL. This suggests that the EMT 384 accentuated the salt content increase, perhaps by increasing 385 the salt content of the intermediate and deep water masses 386 originating from the Eastern basin and circulating in the 387 NWMED. Nevertheless this effect is small compared to the 388 long-term increase occurring during the 1990s.

389 [24] Schroeder et al. [2010] observed that the high heat 390 and salt contents in 2004 were related to an intermediate 391 layer warmer and saltier than the average: they showed that 392 the difference compared to the climatology was the stron393 gest in the 500-1000 m layer. The evolution of the heat and 394 salt contents in each main layer of the average water column 395 over LION in CTRL and NEMT is indicated in Figure 4: 396 surface layer of Atlantic Water $(0-150 \mathrm{~m})$, intermediate 397 layer of Levantine Intermediate Water (LIW, 150-1450 m) 398 and deep layer of WMDW (1450 $\mathrm{m}$ to bottom). The values 399 obtained for the variation of heat and salt contents between 4001987 and 2004 in each layer are indicated for CTRL in 401 Figure 4, as well as the values of the contribution of each 402 layer to the total variation, the trend between 1987 and 4032004 , and the standard deviation of the detrended signal 404 between 1987 and 2004. In the intermediate and deep layers, 405 the 1987-2004 variation is 1 order of magnitude larger than 406 the standard deviation of the detrended signal. The increase 407 in these layers is therefore significant and not due to the 408 interannual variability. On the contrary, in the surface layer, 409 the variation between 1987 and 2004 is of the same order 410 than the standard deviation of the detrended signal: the 411 difference between 1987 and 2004 cannot be clearly 412 attributed to a positive trend, but is rather due to the inter413 annual variability. This can be explained by the fact that 414 contrary to the deep and intermediate layers, the surface 415 layer is directly submitted to the strong seasonal yariability 416 of the atmospheric forcing. Finally during the 1990s, the 417 heat and salt contents significantly increase only in the deep 418 and intermediate layers. The warming and salting of the 419 whole water column is mainly due to the warming and 420 salting of the intermediate layer/that represent $78 \%$ and $42183 \%$, respectively, of the total increase.

422 [25] The evolution between 1961 and 2006 in CTRL of 423 the yearly maximum of the spatial maximum of the daily 424 mixed layer depth (MLD) over LION, $M L D_{\max }$, is pre425 sented in Figure 2 (black line for CTRL). Comparing the 426 evolution of $M L D_{\max }$ with the evolution of the total heat and 427 salt contents shows that those contents increase during the 428 periods of weak convection (1971-1979, 1988-1998) and 429 decrease or remain approximately constant during the peri430 ods of stronger convection (1961-1970, 1981-1987, 1999431 2006). Indeed, when deep convection occurs, the water 432 column is mixed, producing WMDW. When convection 433 ceases after the winter, the salt and heat originally contained 434 in the warm and salty intermediate layer are exported with 435 the WMDW in the deep layer then out of the convection 436 area [Herrmann et al., 2008]. This results in a transfer of 437 heat and salt from the intermediate layer into the deep layer. 438 This abrupt removal (input) of heat and salt from the 439 intermediate layer (into the deep layer) was observed by 440 Schroeder et al. [2010] after the convection event of winter 441 2004-2005. It is reproduced in CTRL, for example after the 442 strong convection events of winters 1980-1981 and 2004-
2005, that both occurred after several winters without deep 443 convection (Figures 4 and 2). Salt and heat are then pro- 444 gressively reintroduced in the intermediate layer when the 445 salty and warm LIW originating from the Eastern basin 446 [Millot, 1999] spreads into the NWMED. If convection does 447 not occur during a few years, the heat and salt contents of 448 the intermediate layer will therefore increase until warm and 449 salty LIW has completely refilled this layer. As will be 450 shown in section 3.3.1, the intensity of deep convection 451 depends on the winter buoyancy loss: deep convection 452 occurs when the winter buoyancy loss is sufficiently strong, 453 enabling the initially stratified water column to be mixed to 454 great depth. Between 1988 and 2001, the winter buoyancy 455 loss was generally lower than the average, explaining that 456 convection was weak during this period (Figure 2). Our 457 results therefore suggest that the exceptionally high heat and 458 salt contents in 2004 were not due to an anomalously high 459 arrival of heat and salt induced by the EMT, but to the 460 absence of strong convection during the 1990s. This absence 461 would have resulted from the weakness of the winter 462 atmospheric buoyancy loss during this period and enabled 463 the heat and salt to accumulate in the intermediate layer. 464

[26] Observed values of MLD available thanks to several 465 oceanographic campaigns reported by Mertens and Schott 466 [1998], Testor and Gascard [2006] and Schröder et al. 467 [2006] are also indicated in Figure 2 (blue squares). Com- 468 paring the data and the model results suggests that the 469 absolute value of the modeled MLD is generally under- 470 estimated. Data are, however, too scarce to validate the 471 representation of the interannual variability of the MLD, 472 which is suggested here to play an important role in the long- 473 term evolution of heat and salt content in the Gulf of Lion. 474 Nevertheless, this comparison put our conclusions into per- 475 spectives, reminding that they are obtained thanks to a given 476 model forced by a given atmospheric data set. We analyze 477 and interpret the results of this model, which is not the reality 478 but a tentative to represent it as well as possible using the 479 state of the art of the models used to simulate the long-term 480 Mediterranean oceanic circulation. It would be necessary to 481 perform a group of other simulations using other ocean 482 models and other atmospheric forcing in order enforce the 483 robustness of our conclusions or to propose alternative 484 explanations. Note, however, that other studies [Sannino 485 et al., 2009] also suggest that due to weak winter surface 486 buoyancy flux, the 1990s was a period of weak convection. 487 3.1.2. Impact of the EMT on the Structure of the Water 488 Column

[27] Analyzing hydrographic data, Gasparini et al. [2005] 490 showed that in the Sicily channel and in the Tyrrhenian 491 subbasin, the EMT resulted in a deepening between 1992492 and 2003 of the heat and salt originating from the Eastern 493 Basin. As a result the saltier and warmer waters progres- 494 sively extended their influence in depth until $1500 \mathrm{~m}$ (see 495 Figure 14 of Gasparini et al. [2005]). Deep water of eastern 496 origin then flows into the NWMED [Millot, 1999], we can 497 therefore expect from those observations in the Tyrrhenian 498 that the EMT induced the deepening of the salty and warm 499 intermediate layer in the NWMED. Indeed, the heat and salt 500 increase extended deeper in CTRL (until 1500 m; Figure 5), 501 in agreement with the observations, than in NEMT where it 502 mainly occurred in the "classical" intermediate layer (200- 503 $1000 \mathrm{~m}$ ). Our modeling study therefore shows an effect of 504 

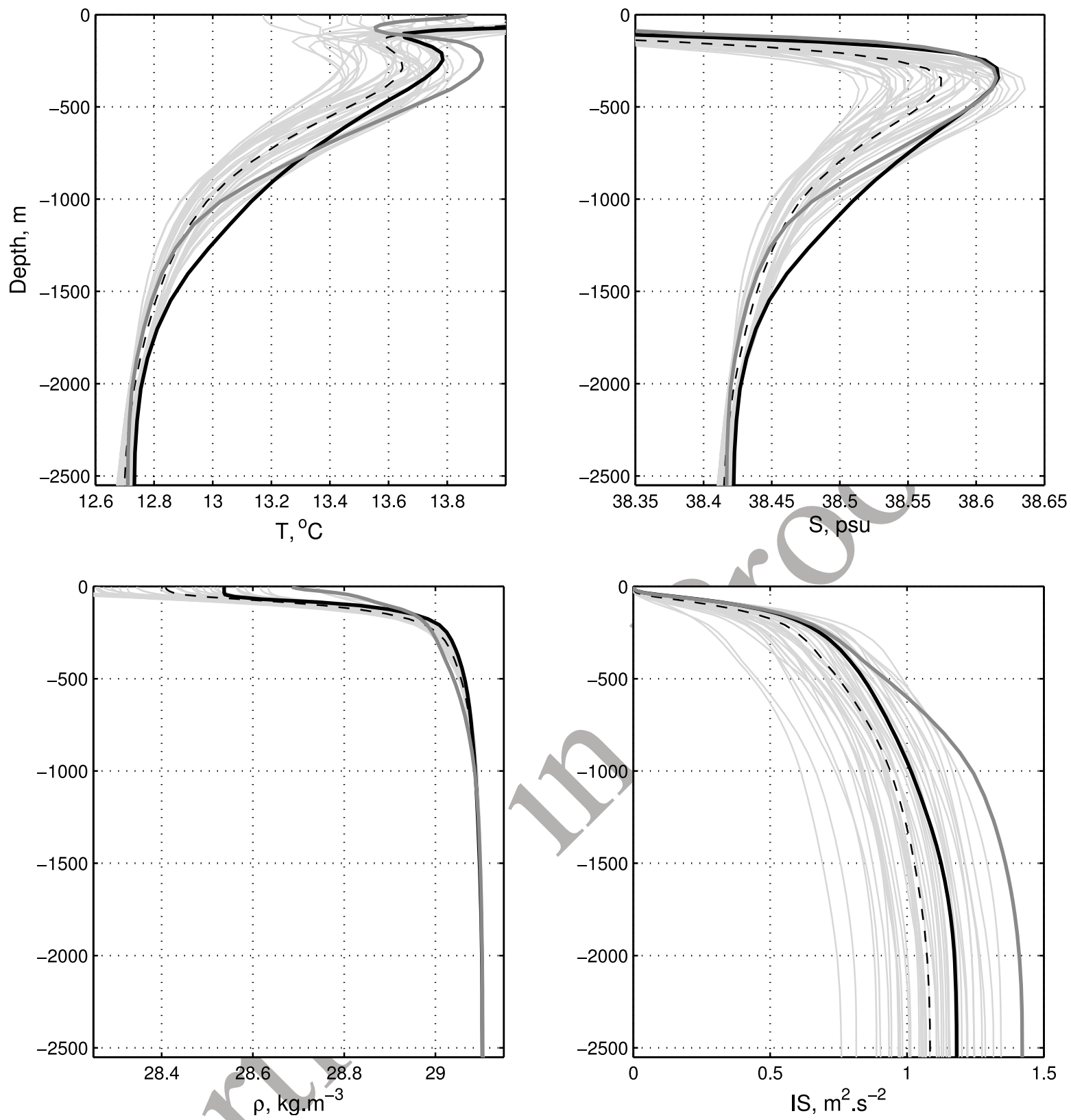

Figure 5. Average temperature, salinity, density, and stratification profiles in December over LION. Light gray lines are 1961-2000 for CTRL. Dashed line is average profile over 1961-2000. Black line is 2004 for CTRL. Dark gray line is 2004 for NEMT.

505 the EMT on the structure of the NWMED water column in 506 agreement with the observations made by Gasparini et al. 507 [2005] and Schroeder et al. [2010]: the EMT induced a 508 deepening of the heat and salt maximum in the NWMED.

509 [28] Gasparini et al. [2005] showed that this deepening 510 was associated with an increase of the density of the warm 511 and salty eastern waters flowing in the intermediate and 512 deep layers of the Western basin. This increase of the 513 density in the intermediate layer is reproduced by the model, 514 as can be seen when comparing the CTRL and NEMT 515 density profiles (Figure 5). The vertical density gradient 516 in these layers consequently decreased. To investigate 517 the effect of this modification of the density profile on the 518 stratification of the NWMED water column, we compute the total buoyancy flux required to mix an initially stratified 519 water column down to the depth $z, \operatorname{IS}(z)$, using the formula 520 used by Herrmann et al. [2008]:

$$
I S(z)=\int_{0}^{z} N^{2}(h) \cdot h \cdot d h=\int_{0}^{z} \frac{-g}{\rho} \frac{\partial \rho}{\partial h} \cdot h \cdot d h
$$

where $\mathrm{N}\left(\mathrm{s}^{-1}\right)$ is the initial Brunt-Väisälä frequency. IS 522 represents an index of the stratification of the water column. 523 The stratification profiles on December 2004 over LION are 524 shown in Figure 5 for CTRL and NEMT. The stratification 525 in NEMT is among the strongest of the whole 1961-2004 526 period, whereas the stratification in CTRL is only slightly 527 above the average. This shows that the EMT induced a 528 
(a)
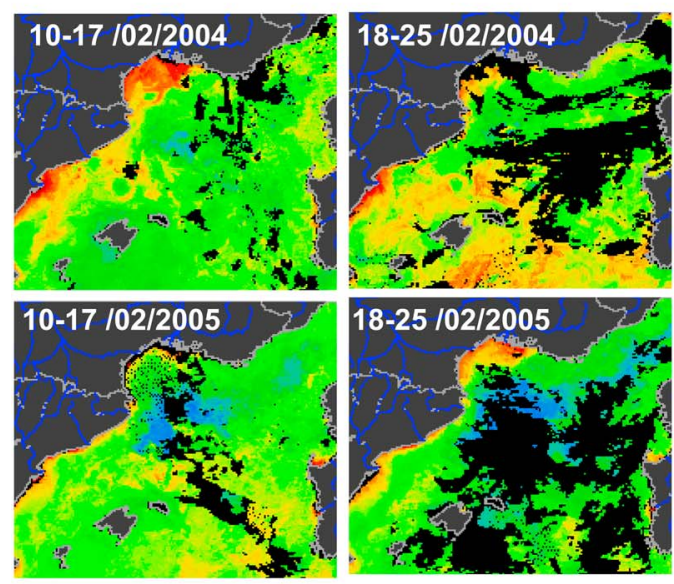
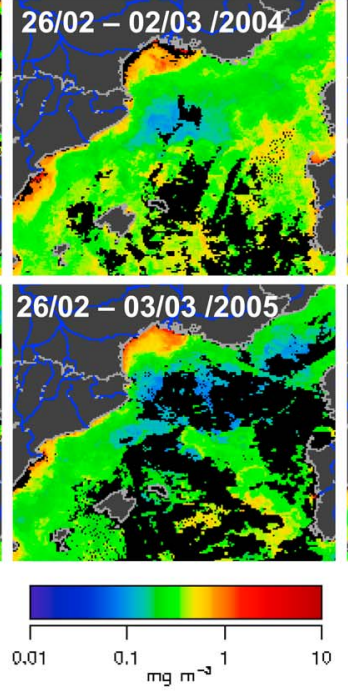

(b)
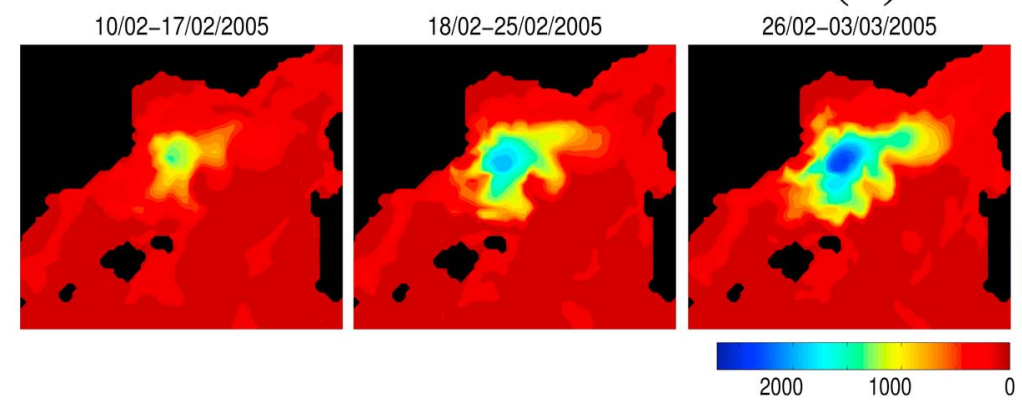
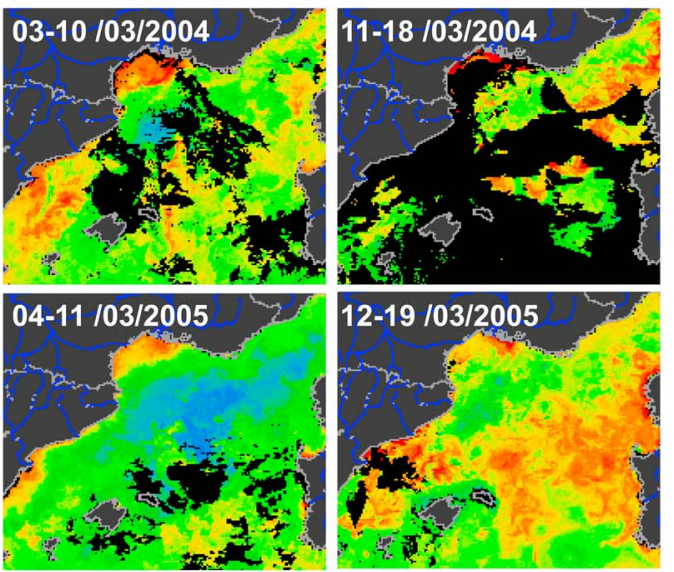

04/03-11/03/2005
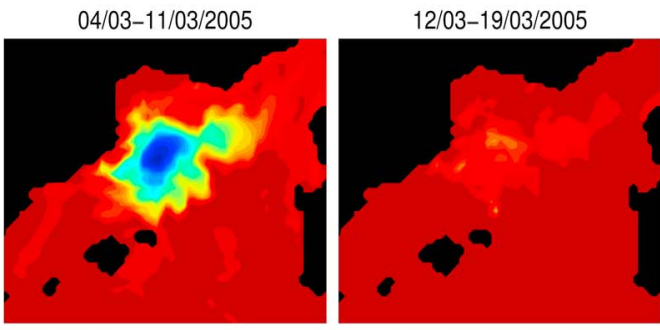

Figure 6. (a) Weekly averaged surface chlorophyll concentration observed by MODIS in the NWMED during the winter convection period (mid-February/mid-March) in (top) 2004 and (bottom) 2005 (unit is $\mathrm{mg} \mathrm{m}^{-3}$ ). (b) Maps of the MLD averaged over the same periods in CTRL (unit is meters).

529 weakening of the NWMED stratification compared with 530 what would have been the case without the EMT. This 531 is due to the fact that $I S(z)$ being proportional to $\int z \times \frac{\partial \rho}{\partial z}$, 532 a decrease of the vertical density gradient in the intermediate 533 and deep layer results in a decrease of $I S$.

\section{3.2. Modeling of the 2005 NWMED Convection Event:} 535 Validation of the CTRL Simulation

536 [29] All the information concerning the 2004-2005 con537 vection event available to us was gathered in order to vali538 date the modeling of this event in CTRL. First, in situ 539 observations available in the literature cited in section 1 540 provide information about the hydrologic characteristics 541 and the structure of the water column in the WMED and 542 about the characteristics of the WMDW. Second, satellite 543 ocean color data provide information about the temporal and 544 spatial evolution of the convection process.

545 3.2.1. Temporal and Spatial Characteristics of the 2005 546 Convection Event

547 [30] The deepest value of $M L D_{\max }$ between 1961 and 5482006 in CTRL is obtained for 2004-2005 (2601 m), one of 549 the four winters of the whole period during which the 550 convection reaches the bottom (MLD $>2000 \mathrm{~m}$ ) in this simulation (Figure 2). Convection during winter 2004-2005 551 is therefore exceptionally strong in CTRL, in agreement 552 with the reported observations.

[31] MODIS Ocean color data available on http://marine. 554 jrc.ec.europa.eu provide an estimate of the extension of the 555 convection area. In this area, strong vertical displacements 556 indeed prevent the phytoplankton from remaining at the 557 surface. The convection area therefore corresponds to the 558 region of low chlorophyll concentration. Figure 6a shows 559 the maps of the 8 day average chlorophyll obtained from 560 MODIS between 10 February and 18 March 2004 and 2005. 561 Comparing the 2004 and 2005 maps shows that the partic- 562 ularly large extension of the convection area in 2005 is well 563 captured by those images.

[32] The extension of the low chlorophyll area is the 565 largest between 18 February and 11 March 2005, indicating 566 that this period was the period of maximum convection. 567 Convection does not seem to occur after 12 March. This is 568 in agreement with Smith et al. [2008] who reported that the 569 water column was strongly mixed in the Catalan sea 570 between 7 and 12 March. 571

[33] WMDW is identified in our simulations as the water 572 of density larger than $29.1 \mathrm{~kg} \mathrm{~m}^{-3}$, following previous 573 
(a)

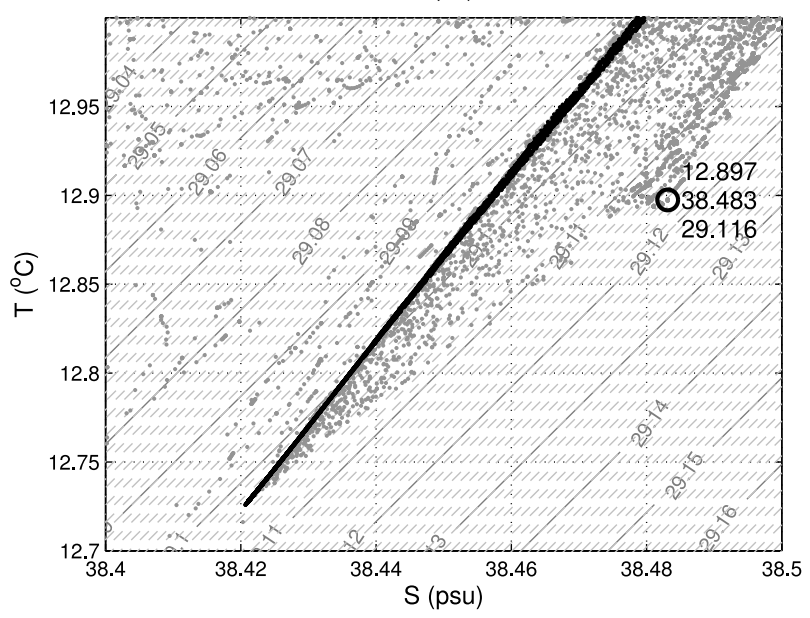

(c)

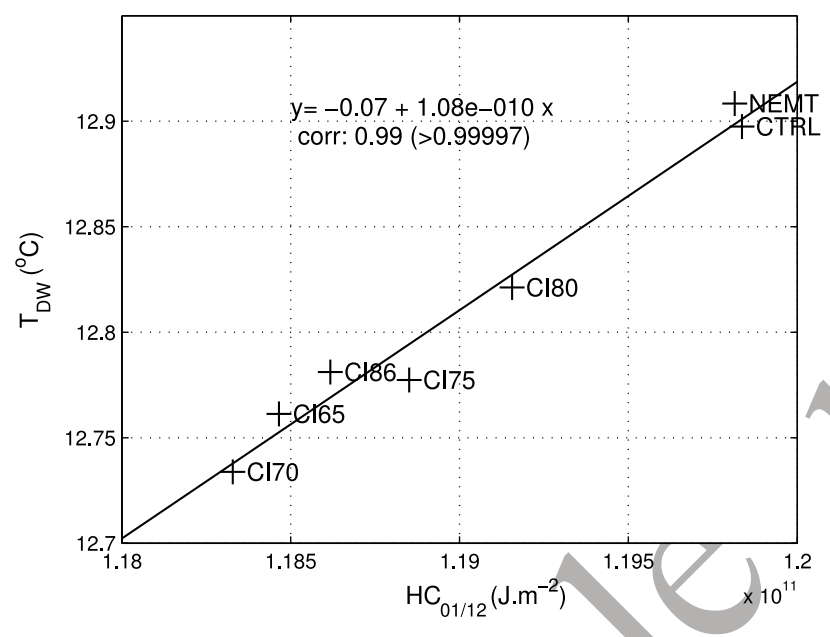

(b)

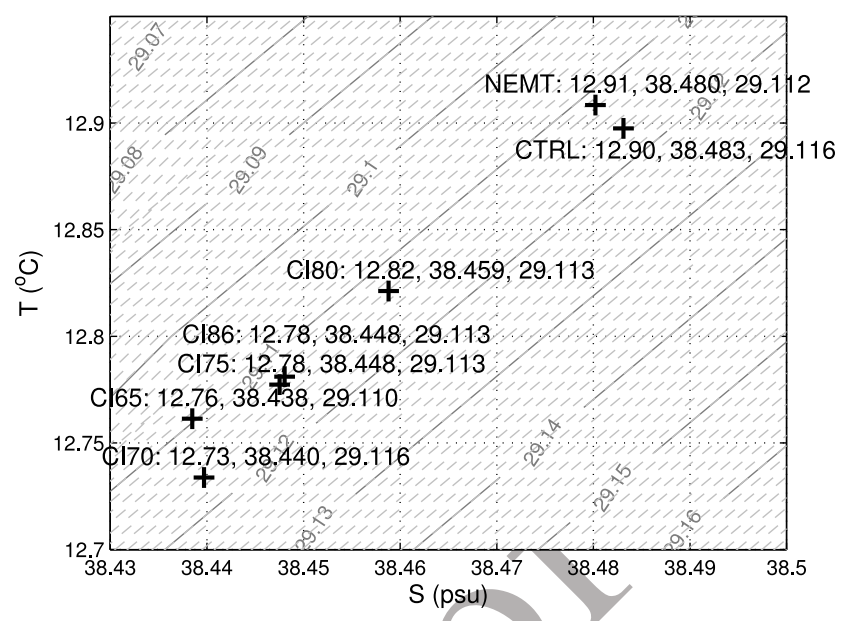

(d)

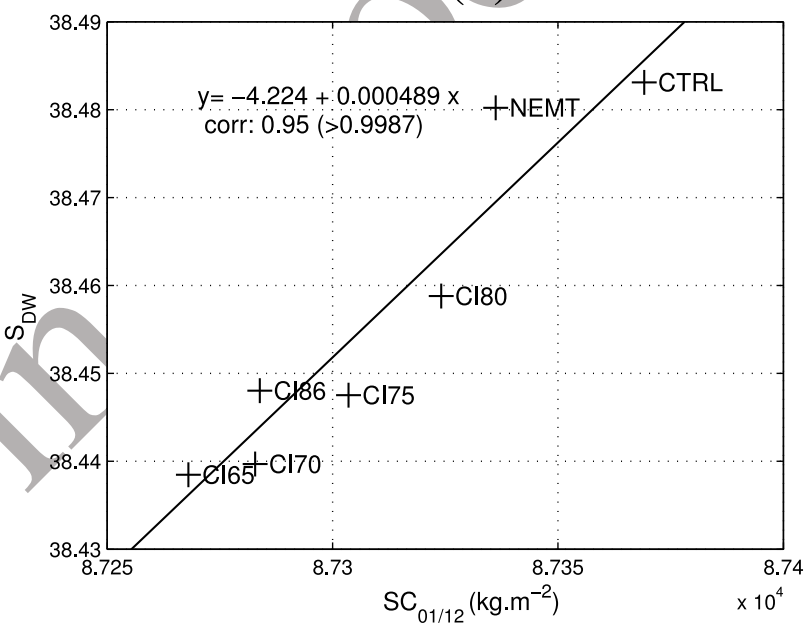

Figure 7. WMDW characteristics in simulations performed under the atmospheric forcing of 20042005. (a) Temperature-salinity diagram of the water present in LION over the whole column before the convection (1 December 2004, black points) and at the date of maximum convection (10 March 2005, gray points) in CTRL: each point corresponds to a point of the model grid. The characteristics of the densest water present in LION on 10 March 2005 are indicated (black circle). (b) Characteristics $\left(\mathrm{T}\left({ }^{\circ} \mathrm{C}\right), \mathrm{S}, \rho\left(\mathrm{kg} \mathrm{m}^{-3}\right)\right)$ of the densest water present in LION at the date of maximum convection (10 March 2005) for each simulation. (c) Relation between the preconvection heat content over LION, $H C_{01 / 12}$, and the WMDW temperature $T_{D W}$. (d) Relation between the preconvection salt content over LION, $S C_{01 / 12}$, and the WMDW salinity $S_{D W}$.

574 modeling and observation studies (see, for example, 575 Marshall and Schott [1999] or Herrmann et al. [2008]). 576 Following Herrmann et al. [2008], the volume of newly 577 formed WMDW $V_{D W}$ is computed each day as the differ578 ence between the volume of WMDW present in the 579 NWMED on this day and the minimum of this volume 580 before the convection event, i.e., in autumn 2004 (equal to $\left.58113.010^{13} \mathrm{~m}^{3}\right): V_{D W}$ represents an anomaly. The WMDW 582 formation rate $\tau_{D W}$ is then computed following Castellari 583 et al. [2000] by dividing $V_{D W}$ by the numbers of seconds 584 in 1 year. Times series between 1 December 2004 and 30 585 April 2005 of the modeled maximum MLD over LION $586 M L D_{\max }$ and of $V_{D W}$ are shown in Figure $3 \mathrm{~b}$ (black line for 587 CTRL). The evolution of the convection event follows the 588 atmospheric chronology: each atmospheric event of strong buoyancy loss induces an abrupt increase of $M L D_{\max }$ and 589 $V_{D W}$. The mixed layer reaches $1500 \mathrm{~m}$ on 17 February, and 590 the bottom is reached between 27 February and 13 March 591 $\left(M L D_{\max }>2000 \mathrm{~m}\right)$, with a small decrease between 1 March 592 and 3 March induced by a decrease of buoyancy loss. This is 593 in agreement with the satellite and in situ observations. The 594 maximum of $V_{D W}$ is reached on 10 March after the last 595 atmospheric event. It is equal to $3.6610^{13} \mathrm{~m}^{3}$, corresponding 596 to a formation rate $\tau_{D W}$ of $1.16 \mathrm{~Sv}$. This value is consistent 597 with Schroeder et al. [2008], who estimated from in situ 598 observations that the cumulated formation rate for winters 599 2004-2005 and 2005-2006 was approximately equal to 600 $2.4 \mathrm{~Sv}$. Then, as soon as the atmospheric $B L$ becomes neg- 601 ative, $M L D_{\max }$ abruptly decreases to zero: restratification of 602 the water column begins, and $V_{D W}$ starts to decrease. The 603 
Table 3. Preconvection and Convection Characteristics for Each Simulation ${ }^{\mathrm{a}}$

\begin{tabular}{|c|c|c|c|c|c|c|c|c|c|c|}
\hline $\mathrm{t} 3.2$ & Name $^{\mathrm{b}}$ & $\begin{array}{l}\mathrm{HC} \text { on } 1 \text { December } \\
\left(10^{11} \mathrm{~J} \mathrm{~m}^{-2}\right)\end{array}$ & $\begin{array}{l}\text { SC on } 1 \text { December } \\
\quad\left(10^{4} \mathrm{~kg} \mathrm{~m}^{-2}\right)\end{array}$ & $\begin{array}{l}\text { IS on } 1 \text { December } \\
\left(\mathrm{m}^{2} \mathrm{~s}^{-2}\right)\end{array}$ & $\begin{array}{l}T_{D W} \\
\left({ }^{\circ} \mathrm{C}\right)\end{array}$ & $S_{D W}$ & $\begin{array}{c}\rho_{D W} \\
\left(\mathrm{~kg} \mathrm{~m}^{-3}\right)\end{array}$ & $\begin{array}{c}\tau_{D W} \\
(\mathrm{~Sv})\end{array}$ & $\begin{array}{l}M L D_{\max } \\
\quad(\mathrm{m})\end{array}$ & $\begin{array}{l}M L D_{\text {mean }} \\
\quad(\mathrm{m})\end{array}$ \\
\hline $\mathrm{t} 3.3$ & CTRL 2004-2005 & 1.198 & 8.737 & 1.02 & 12.90 & 38.483 & 29.116 & 1.16 & 2601 & 943 \\
\hline $\mathrm{t} 3.4$ & CTRL 1965-1966 & 1.184 & 8.727 & 1.11 & no WMDW & & & 0.07 & 372 & 94 \\
\hline t3.5 & CTRL 1970-1971 & 1.185 & 8.729 & 1.02 & 12.81 & 38.451 & 29.110 & 0.42 & 2398 & 472 \\
\hline t3.6 & CTRL 1975-1976 & 1.186 & 8.731 & 0.90 & no WMDW & & & 0.14 & 1416 & 264 \\
\hline $\mathrm{t} 3.7$ & CTRL 1980-1981 & 1.188 & 8.733 & 0.84 & 12.90 & 38.479 & 29.113 & 0.85 & 2382 & 510 \\
\hline $\mathrm{t} 3.8$ & CTRL 1986-1987 & 1.188 & 8.728 & 1.21 & no WMDW & & & 0.06 & 1333 & 223 \\
\hline t3.9 & CI65 & 1.185 & 8.727 & 1.15 & 12.76 & 38.438 & 29.110 & 0.72 & 2584 & 729 \\
\hline $\mathrm{t} 3.10$ & CI70 & 1.183 & 8.728 & 0.98 & 12.73 & 38.440 & 29.116 & 1.19 & 2645 & 923 \\
\hline $\mathrm{t} 3.11$ & CI75 & 1.189 & 8.730 & 1.05 & 12.78 & 38.448 & 29.113 & 1.02 & 2604 & 804 \\
\hline $\mathrm{t} 3.12$ & CI80 & 1.192 & 8.732 & 1.05 & 12.82 & 38.459 & 29.113 & 1.01 & 2593 & 749 \\
\hline t3.13 & CI86 & 1.186 & 8.728 & 1.10 & 12.78 & 38.448 & 29.113 & 0.84 & 2543 & 765 \\
\hline $\mathrm{t} 3.14$ & AF65 & 1.198 & 8.737 & 1.01 & no WMDW & & & 0.06 & 433 & 118 \\
\hline t3.15 & AF70 & 1.200 & 8.737 & 1.06 & 13.04 & 38.513 & 29.110 & 0.54 & 1883 & 564 \\
\hline $\mathrm{t} 3.16$ & AF75 & 1.196 & 8.737 & 0.86 & no WMDW & & & 0.10 & 1199 & 282 \\
\hline $\mathrm{t} 3.17$ & AF80 & 1.195 & 8.738 & 0.77 & 12.92 & 38.488 & 29.115 & 1.63 & 2562 & 768 \\
\hline t3.18 & AF86 & 1.200 & 8.736 & 1.15 & no WMDW & & & 0.08 & 1333 & 291 \\
\hline $\mathrm{t} 3.19$ & NEMT 2004-2005 & 1.198 & 8.734 & 1.24 & 12.91 & 38.480 & 29.112 & 0.57 & 2429 & 746 \\
\hline
\end{tabular}

t3.20 a Given are average heat and salt contents and stratification index at $1000 \mathrm{~m}$ over LION on 1 December (HC, SC, and IS), WMDW characteristics $\left(T_{D W}\right.$, t3.21 $S_{D W}$, and $\left.\rho_{D W}\right)$, WMDW formation rate $\left(\tau_{D W}\right)$, winter maximum of the maximum MLD over LION (MLD max $)$, and winter maximum of the average MLD t3.22 over LION $\left(M L D_{\text {mean }}\right)$. When $M L D_{\max }<1500 \mathrm{~m}$ the convection is not considered as deep but intermediate. No WMDW is formed.

t3.23 ${ }^{\mathrm{b}}$ Year is also given for CTRL and NEMT.

604 chronology of the convection event reproduced by the model 605 is therefore in good agreement with the chronology deduced 606 from the available observations.

607 [34] The modeled area of convection corresponds to the 608 area obtained from the ocean color data, as can be seen when 609 comparing the maps of the 8 day average of the modeled 610 MLD between 10 February and 18 March shown in Figure 6b 611 and the corresponding ocean color maps. At each period, the 612 size and position of the modeled convection area corresponds 613 to the size and position of the observed low chlorophyll 614 concentration area. The extension of the convection area is 615 the largest between 26 February and 11 March, as the 616 extension of the low chlorophyll concentration area.

617 3.2.2. Characteristics of WMDW Formed in 2005

618 [35] Figure 7a shows the temperature-salinity diagram 619 of the water present in LION before the convection event 620 (1 December 2004) and when the convection reaches its 621 maximum (10 March 2005). "Old" WMDW, i.e., WMDW 622 formed before winter 2004-2005, can be identified on 6231 December as the water present in LION and denser than $62429.10 \mathrm{~kg} \mathrm{~m}^{-3}$ : in CTRL, characteristics of old WMDW are $625 \sim 12.72-12.80^{\circ} \mathrm{C}$ and $\sim 34.42-38.44$. They belong to the 626 range of the observed characteristics of old WMDW reported 627 in the literature $\left(12.75-92^{\circ} \mathrm{C}, 38.41-47\right.$; see Table 1). 628 WMDW formed during winter 2004-2005 can be identified 629 as the densest water present on 10 March. Its characteristics $630\left(T_{D W}=12.90^{\circ} \mathrm{C}, S_{D W}=38.48\right.$ and $\left.\rho_{D W}=29.116 \mathrm{~kg} \mathrm{~m}^{-3}\right)$ are 631 in very good agreement with the observed characteristics of $632 \mathrm{WMDW}$ formed in $2005\left(12.87-90^{\circ} \mathrm{C}, 38.47-50,29.113\right.$ $633130 \mathrm{~kg} \mathrm{~m}^{-3}$; see Table 1). The change of temperature and 634 salinity between old and "new" WMDW is therefore also 635 correctly reproduced $\left(\sim+0.1-0.2^{\circ} \mathrm{C}\right.$ and $\left.\sim+0.04-0.06\right)$.

\section{3.3. Analysis of the Sensitivity Simulations: Which 637 Factors Were Responsible for the Characteristics 638 of the 2005 Convection Event?}

639 [36] Having shown that the CTRL simulation represents 640 correctly the 2004-2005 convection event, we now analyze 641 the sensitivity simulations in order to determine the respective contributions of the oceanic and atmospheric 642 conditions to the characteristics of this event. 643 3.3.1. Why Was the 2004-2005 Convection Event 644 Exceptionally Strong?

[37] In this section we investigate the factors responsible 646 for the exceptional intensity of the 2005 convection event in 647 terms of mixed layer depth and volume of newly formed 648 WMDW: we examine the influence of the stratification of 649 the water column at the beginning of the convection, of the 650 EMT and of the atmospheric conditions during 2004. 651 3.3.1.1. Impact of the Oceanic Conditions of 2004-2005 652 and of the EMT on the Convection Intensity 653

[38] To investigate the role played by the oceanic condi- 654 tions in the intensity of the 2004-2005 convection event, we 655 examine the simulations where the atmospheric forcing is 656 the one of year 2004-2005 but where the initial oceanic 657 conditions vary: CIXX and year 2004-2005 of CTRL and 658 NEMT. For those simulations, the evolution of the maxi- 659 mum MLD over LION, $M L D_{\max }$, and of the volume of 660 newly formed WMDW, $V_{D W}$, is presented in Figure 3b. The 661 chronology of the convection event is the same for all those 662 simulations: each event of strong atmospheric buoyancy loss 663 (highlighted in gray in Figure 3) induces an abrupt deep- 664 ening of the mixed layer and an increase of $V_{D W}$, which then 665 remain relatively stable. The maximum of the convection 666 intensity, corresponding to the maximum of $V_{D W}$, is reached 667 for all the simulations on 10 March, just after the last event 668 of strong buoyancy loss occurring in March. At this time, 669 the convection reaches the bottom in all the simulations: 670 $M L D_{\max }$ varies between $2430 \mathrm{~m}$ for NEMT and $2645 \mathrm{~m}$ for 671 CTRL (Table 3). The MLD then abruptly decreases when 672 the buoyancy loss becomes positive, after 13 March, and 673 $V_{D W}$ begins to decrease.

674

[39] First, this shows that the chronology of the convec- 675 tion in terms of deepening/shallowing of the mixed layer 676 and increase/decrease of $V_{D W}$ is driven by the succession of 677 atmospheric events. For year 2004-2005, this resulted in a 678 strong bottom convection. Second, although bottom con- 679 vection occurs in all those simulations, the volume of newly 680 
(a)

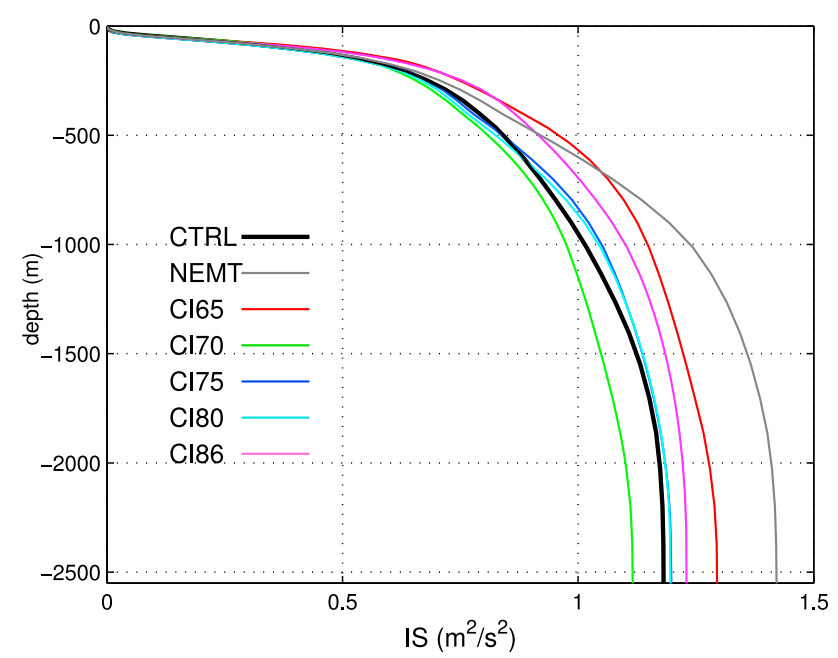

(b)

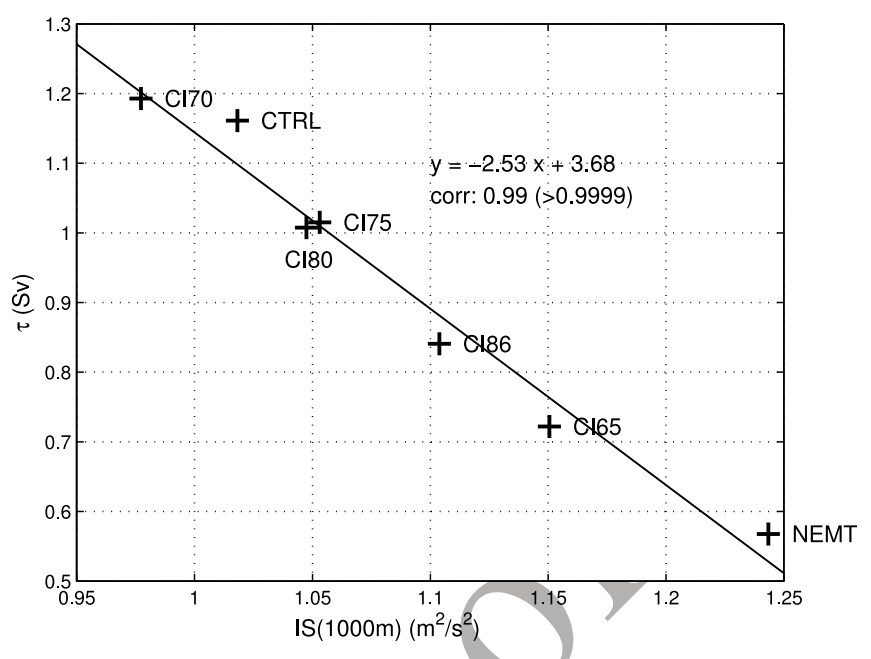

Figure 8. (a) For simulations performed under the 2004-2005 atmospheric forcing, average profile over LION of the stratification index on 1 December, $I S(z)$. (b) Relation between the ayerage stratification index over LION at $1000 \mathrm{~m}$ on 1 December 2004, IS(1000m), and the WMDW formation rate, $\tau_{D W}$.

681 formed WMDW varies by a factor of 2 between the most 682 and the less productive simulations $\left(\tau_{D W} \sim 0.7 \mathrm{~Sv}\right.$ in CI65 683 and $\sim 1.2 \mathrm{~Sv}$ in CI70; Figure $3 \mathrm{~b}$ and Table 2). This vari684 ability of $\tau_{D W}$ is actually related to the variability of the 685 stratification of the water column at the beginning of the 686 convection: the more stratified the column is, the more 687 difficult it is to mix it. To show that, we examine the profiles 688 of $I S(z)$ before the convection event on 1 December for year 6892004 of NEMT, CTRL and CIXX (Figure 8a). The most 690 stratified water column is obtained in NEMT, and CTRL is 691 among the simulations with the less stratified water column. 692 The largest winter maximum of the average $M L D$ over $693 \mathrm{LION}$ in 2005 is obtained for CTRL: $M L D_{\text {mean }}=943 \mathrm{~m}$, 694 slightly less than $1000 \mathrm{~m}$ (Table 3 ). We therefore compute 695 for each simulation the stratification index of the water 696 column at $1000 \mathrm{~m}$ before the convection event on 1 December 6972004 (Table 2). Performing a regression analysis between the 698 WMDW formation rate $\tau_{D W}$ and $I S(1000 \mathrm{~m}, 1$ December 699 2004), we obtain a strong linear relationship with a corre700 lation factor of 0.99 (SL $>0.9999$ ) (Figure $8 b$ ). For given 701 atmospheric conditions, here those of winter 2004-2005, the 702 variability of the intensity of deep convection in terms of 703 volume of newly formed WMDW is therefore directly related 704 to the variability of the stratification at the beginning of the 705 convection, which facilitates or hinders the mixing of the 706 water column.

707 [40] Comparing the $I S$ profiles in December 2004 in 708 NEMT and CTRL, we showed in section 3.1 that the EMT 709 induced a weakening of the stratification in the NWMED. 710 As a result, the intensity of deep convection in terms of 711 WMDW formed is twice stronger in CTRL than in NEMT. 712 3.3.1.2. Impact of the Atmospheric Conditions of 20047132005 on the Convection Intensity

714 [41] Figure 5 shows the profiles of $\operatorname{IS}(z)$ before the con715 vection event on 1 December for all the years of the CTRL 716 simulation and for year 2004 of NEMT. The water column 717 on 1 December 2004 in NEMT is the most stratified of all the years; however, the convection reaches the bottom. This 718 suggests that the atmospheric buoyancy loss in 2004-2005 719 played the most determining role in the intensity of the 720 convection event: it was so strong that convection could have 721 reached the bottom even for the most stratified conditions. 722

[42] To confirm the influence of the atmospheric condi- 723 tions on the intensity of the 2004-2005 convection event, 724 we examine the simulations where the initial oceanic con- 725 ditions are those of August 2004 but where the atmospheric 726 forcing varies: AFXX and year 2004-2005 of CTRL. For 727 those simulations, the evolution of the atmospheric buoy- 728 ancy loss, of $M L D_{\max }$ and of $V_{D W}$ is presented in Figure 9. 729 The variability of the convection depth and newly formed 730 WMDW volume induced by the atmospheric forcing is 731 much larger than the variability induced by the oceanic 732 conditions: there are simulations with no convection (AF65, 733 $\left.M L D_{\max }=433 \mathrm{~m}\right)$ or intermediate convection $(1000 \mathrm{~m}<734$ $M L D_{\max }<1500 \mathrm{~m}, \mathrm{AF70}$, AF86) and practically no 735 WMDW formed ( $\left.\tau_{D W}<0.1 \mathrm{~Sv}\right)$, and simulations with $\tau_{D W} 736$ varying between $0.5 \mathrm{~Sv}$ and $1.6 \mathrm{~Sv}$ with deeper convection 737 $\left(\mathrm{AF} 75, M L D_{\max }=1883 \mathrm{~m}\right)$ or even bottom convection 738 $\left(M L D_{\max }>2000 \mathrm{~m}, \mathrm{AF} 80, \mathrm{CTRL}\right)$. This confirms that the 739 factor predominantly responsible for the intensity of deep 740 convection in 2004-2005 was the atmospheric forcing rather 741 than the oceanic conditions: with different initial oceanic 742 conditions of another autumn bottom convection would 743 have occurred anyway, whereas with different atmospheric 744 conditions there could have been no convection, interme- 745 diate convection or bottom convection. $\quad 746$

[43] Which aspect of the atmospheric forcing more pre- 747 cisely drives the convection? We saw that the succession of 748 strong buoyancy loss event induces the deepening of the 749 mixed layer during the winter, corresponding to the violent 750 mixing phase of deep convection defined by Marshall and 751 Schott [1999]. We therefore expect the variability of the 752 intensity of deep convection to be related to the variability 753 of the cumulated buoyancy loss over this phase. However, 754 


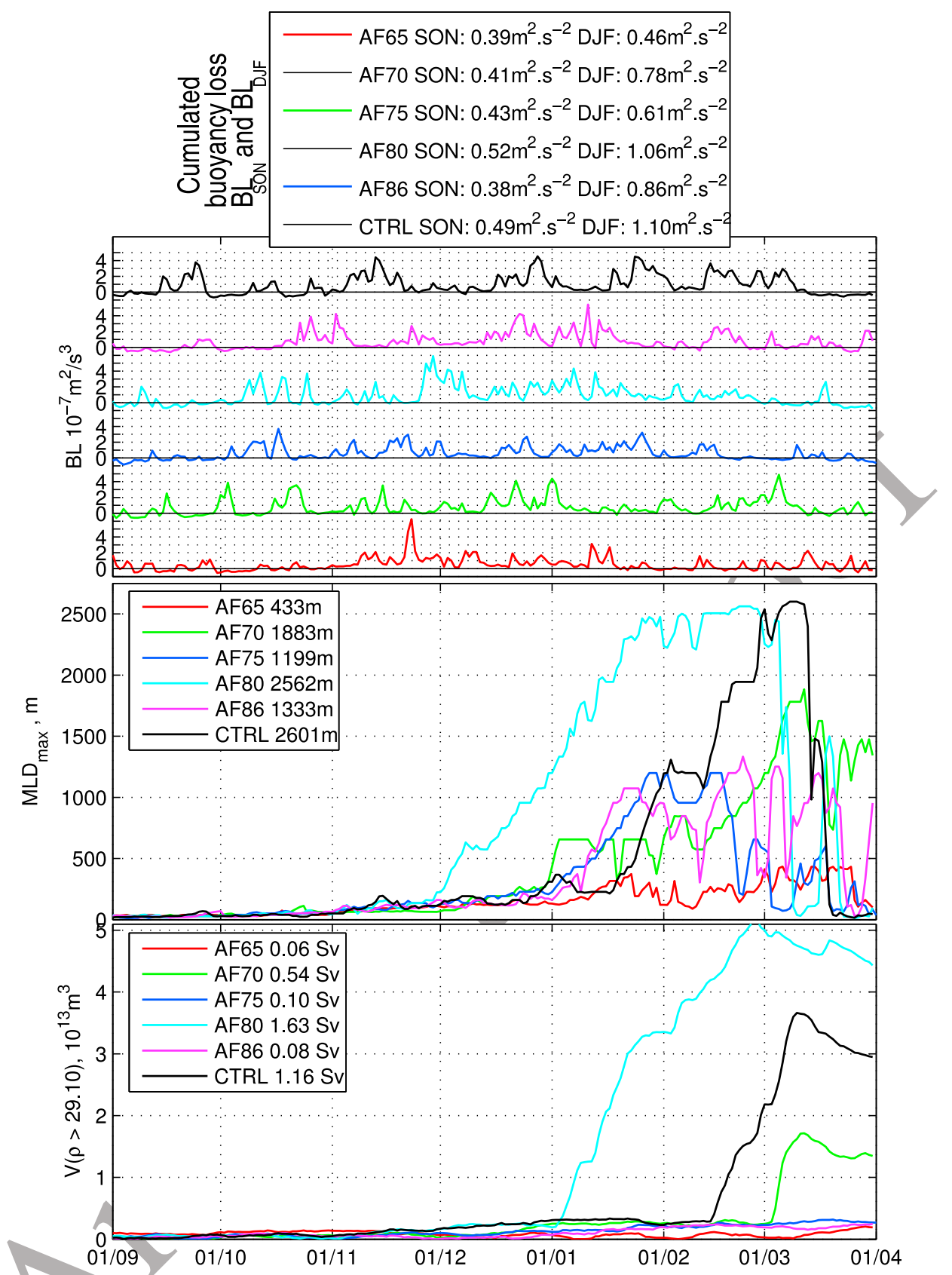

Figure 9. For simulations performed with the initial oceanic conditions of August 2004 of CTRL (AFXX and year 2004-2005 of CTRL), time series between September and March of the average buoyancy loss over LION, $B L$; of the maximum MLD over LION, $M L D_{\max }$; and of the volume of newly formed WMDW, $V_{D W}$. For each simulation we indicate the values of (top) the buoyancy loss cumulated over September-November and December-February, of (middle) the maximum of $M L D_{\max }$, and of (bottom) the WMDW formation rate.

755 the autumn atmospheric buoyancy loss before this phase, $\mathrm{i}$. 756 e., during the preconditioning phase [Marshall and Schott, 757 1999], certainly also plays an important role: it partici758 pates to the weakening of the stratification of the water 759 column. The times series of the mean atmospheric buoyancy 760 loss over LION during September-November, December761 February, and September-February are presented in Figure 2. 762 For simulations performed with the same initial oceanic 763 conditions, the values of the cumulated buoyancy loss during those periods, $B L_{S O N}, B L_{D J F}$ and $B L_{S O N D J F}$, are 764 reported in Figure 9 (top). The results suggest that an 765 atmospheric buoyancy loss stronger than the average is 766 necessary both during the preconditioning and during the 767 violent mixing in order to produce deep convection. In 768 particular, in CTRL and AF80, i.e., the two simulations 769 where convection reaches the bottom, buoyancy losses are 770 significantly stronger than the average over 1960-2006 771 ( $B L_{S O N}$ is equal to 0.49 and $0.52 \mathrm{~m}^{2} \mathrm{~s}^{-2}$ in CTRL and 772 
773 AF80, respectively, versus an average value of $0.48 \mathrm{~m}^{2} \mathrm{~s}^{-2}$, 774 and $B L_{D J F}$ is equal to 1.10 and $1.06 \mathrm{~m}^{2} \mathrm{~s}^{-2}$ versus $0.63 \mathrm{~m}^{2}$ $\left.775 \mathrm{~s}^{-2}\right)$. On the contrary in AF65 and AF75, $B L_{S O N}(0.39$ and $7760.43 \mathrm{~m}^{2} \mathrm{~s}^{-2}$, respectively) and $B L_{D J F}\left(0.46\right.$ and $0.61 \mathrm{~m}^{2} \mathrm{~s}^{-2}$, 777 respectively) are both smaller than the average, and the 778 MLD does not exceed $1500 \mathrm{~m}$. However, some situations 779 are not so straightforward: AF86 does not produce deep 780 convection whereas AF70 does, though their values of $781 B L_{D J F}\left(0.86\right.$ and $0.78 \mathrm{~m}^{2} \mathrm{~s}^{-2}$, respectively) are both larger 782 than the average and their values of $B L_{S O N}\left(0.38 \mathrm{~m}^{2} \mathrm{~s}^{-2}\right.$ and $7830.41 \mathrm{~m}^{2} \mathrm{~s}^{-2}$, respectively) are both smaller than the average. 784 More generally, examining the time series of the atmo785 spheric buoyancy loss and of the maximum MLD between 7861961 and 2006 in CTRL (Figure 2) shows that it is very 787 difficult to find a clear relationship between $B L$ and $788 M L D_{\max }$ : see for example winters 1969-1970, 1975-1976 789 and 1986-1987. It would certainly be necessary to consider 790 the influence of other factors like the frequency and dura791 tion of the atmospheric events. A much larger amount of 792 simulations would be necessary to build a relevant indicator 793 of atmospheric conditions to which the interannual vari794 ability of the intensity of deep convection could be related. 795 This is, however, beyond the scope of this study, that 796 focuses on the 2004-2005 case.

797 [44] Finally, our sensitivity simulations suggest that the 798 strong atmospheric buoyancy loss observed both during 799 autumn 2004 and winter 2004-2005, i.e., during the pre800 conditioning and the violent mixing, was the major factor at 801 the origin of the intensity of the convection observed this 802 year. The particularly weak stratification of the water col803 umn in December 2004 induced by the EMT would have 804 then accentuated the effect of this strong atmospheric con805 ditions and potentially doubled the volume of WMDW 806 formed, but would not have fundamentally modify the 807 convection process.

808 3.3.2. Why Was the WMDW Formed in 2005 809 Exceptionally Warm and Salty?

810 [45] In this section we examine the contributions of the 811 oceanic and atmospheric conditions before and during the 812 convection event of 2004-2005 to the characteristics of 813 the WMDW formed in 2005.

814 3.3.2.1. Impact of the Oceanic Conditions Before and 815 During the 2004-2005 Convection Event on the WMDW 816 Characteristics

817 [46] To investigate the influence of the initial oceanic 818 conditions on the characteristics of the WMDW formed in 819 2004-2005, we examine the simulations where the atmo820 spheric forcing is the one of year 2004-2005 but where the 821 initial oceanic conditions vary: CIXX and year 2004-2005 of 822 CTRL and NEMT (see section 2.3.2). For those simulations, 823 the characteristics of WMDW formed during winter 20048242005 , corresponding to the densest water found in LION at 825 the date of maximum convection (10 March 2005; see 826 section 3.3.1), are indicated in Table 3 and in Figure $7 \mathrm{~b}$. 827 WMDW produced in the CIXX simulations corresponds to 828 old WMDW (12.73-12.82 ${ }^{\circ} \mathrm{C}, 38.43-38.46$; see Table 1), 829 whereas WMDW produced in CTRL but also in NEMT 830 corresponds to new WMDW $\left(\sim 12.9^{\circ} \mathrm{C}, \sim 38.48\right.$; see Table 1$)$. 831 When convection reaches the bottom, which is the case in 832 all the simulations examined here (Figure 3), WMDW is 833 formed by mixing of the whole water column. Therefore, we can expect the temperature and salinity of newly formed 834 WMDW to depend on the heat and salt contents of this water 835 column just before the convection. To confirm this 836 hypothesis, we perform a linear regression analysis between 837 the WMDW characteristics and the average heat and salt 838 contents over LION on 1 December, $H C_{01 / 12}$ and $S C_{01 / 12} 839$ (Figures $7 \mathrm{c}$ and $7 \mathrm{~d}$ ). Values of $H C_{01 / 12}$ and $S C_{01 / 12}$ are 840 reported in Table 3. $T_{D W}$ and $S_{D W}$ are linearly related to 841 $H C_{01 / 12}$ and $S C_{01 / 12}$, respectively, with correlation factors 842 larger than 0.95 ( $\mathrm{SL}>0.99)$. The fact that WMDW produced 843 in 2005 corresponds to old WMDW characteristics in the 844 $\mathrm{CI} X X$ simulations and to new WMDW in CTRL suggests 845 that the exceptional atmospheric heat and salt losses that 846 occurred during winter 2004-2005 were not responsible for 847 the observed change of WMDW characteristics, and that this 848 change was rather due to the evolution of the oceanic heat 849 and salt contents until 2004.

850

[47] To investigate the contribution of the oceanic lateral 851 fluxes of heat and salt during the convection to the char- 852 acteristics of the WMDW formed in 2005, we perform heat 853 and salt budgets over LION between $t_{\text {init }}=1$ December 854 2004 and $t \leq t_{\text {fin }}=31$ March 2005 for simulations performed 855 under the atmospheric forcing of 2004-2005. During this 856 period, the variation of heat content over LION is equal to 857 the sum of the cumulated surface and lateral fluxes of heat, 858 and the variation of salt content is equal to the cumulated 859 lateral flux of salt:

$$
\begin{aligned}
& \Delta_{t_{\text {init }-t}} H C=\int_{t_{\text {init }}}^{t} H F_{\text {lat }}(t) d t+\int_{t_{\text {init }}}^{t} H F_{\text {surf }}(t) d t \\
& \Delta_{t_{\text {init }}-t} S C=\int_{t_{\text {init }}}^{t} S F_{\text {lat }}(t) d t
\end{aligned}
$$

[48] Note that surface freshwater flux associated to 861 evaporation/precipitation (see section 2.2) does not appear 862 in this equation. Indeed, freshwater flux does not modify the 863 total salt content over the water column: there is no flux of 864 salt through the ocean/atmosphere boundary, neither the 865 water that evaporates nor the rainwater contain salt. How- 866 ever, surface freshwater flux induces a variation of the 867 whole volume, and therefore a concentration/dilution that 868 results in a modification of the average salinity. Rigorously, 869 we should relate the salinity of DW to the average salinity 870 over the water column rather than to the total salt content. 871 The following scale analysis shows that this is equivalent. 872

[49] The variation of salinity induced by a change of vol- 873 ume $d V$ due to evaporation/precipitation is equal to $d S_{W F}=874$ $-S \frac{d V}{V}$. The variation of salinity induced by a variation of 875 salt content $\triangle S C$ is equal to $d S_{H C}=\frac{\Delta S C}{\rho V}$. Among winters 876 examined in our sensitivity simulations, deep convection 877 occurs during winters 1970-1971, 1980-1981 and 2004- 878 2005. Between December and February, the net freshwater 879 flux $W F_{D J F}$ and the initial salt content on 1 December $S C_{01 / 12}, 880$ in CTRL over the surface area are equal to $W F_{D J F} \sim 3.9 \mathrm{~mm} 881$ $\mathrm{d}^{-1}$ and $S C_{01 / 12} \sim 8.729 \times 10^{7} \mathrm{~g} \mathrm{~m}^{-2}$, respectively, in 1970- 882 $1971, W F_{D J F} \sim 3.6 \mathrm{~mm} \mathrm{~d}^{-1}$ and $S C_{01 / 12} \sim 8.733 \times 10^{7} \mathrm{~g} 883$ $\mathrm{m}^{-2}$ in $1980-1981$ and $W F_{D J F} \sim 4.4 \mathrm{~mm} \mathrm{~d}^{-1}$ and $S C_{01 / 12} \sim 884$ $8.737 \times 10^{7} \mathrm{~g} \mathrm{~m}^{-2}$ in 2004-2005. Those values provide an 885 estimate of the interannual variability of winter freshwater 886 

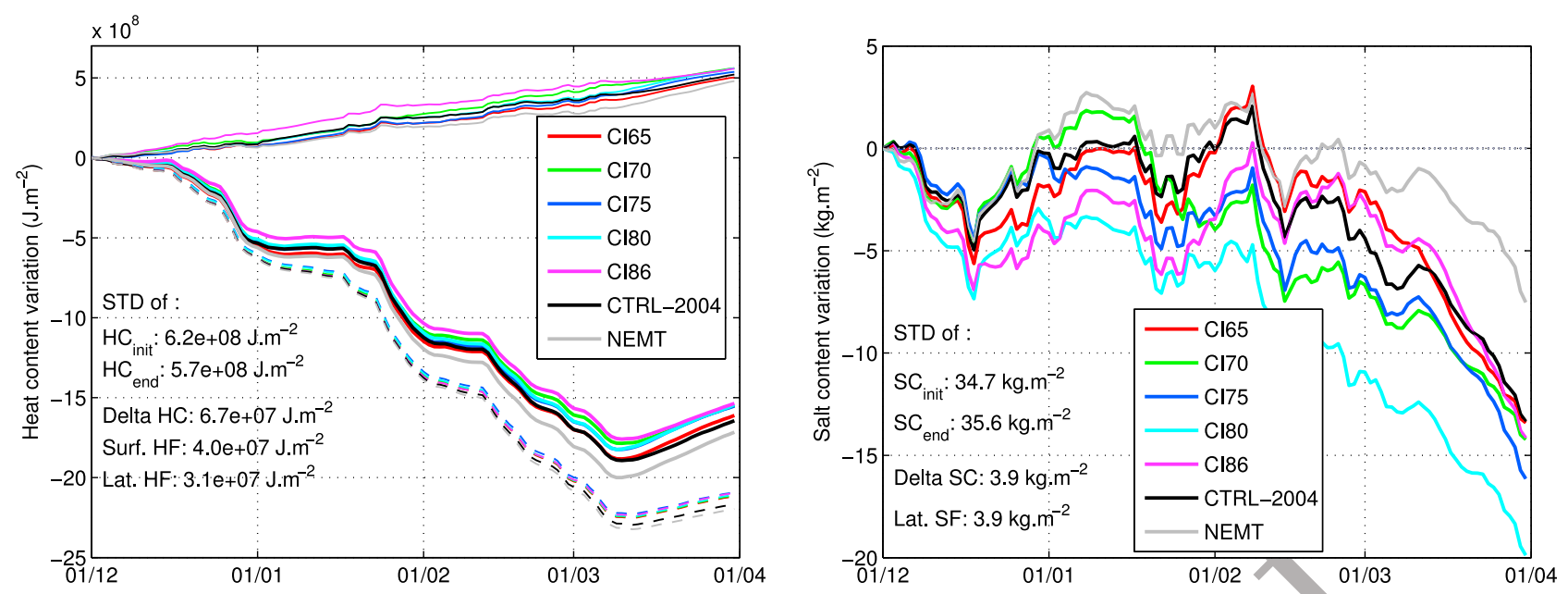

Figure 10. (left) Heat and (right) salt budgets over LION between December 2004 and March 2005 in the simulations performed under the atmospheric forcing of 2004-2005. Daily time series of the variation of the total heat and salt contents ( $H C$ and $S C$, bold lines), of the cumulated atmospheric heat flux $\left(H F_{\text {surf }}\right.$, dashed lines), and of the cumulated lateral heat and salt fluxes $\left(H F_{\text {lat }}\right.$ and $S F_{\text {lat }}$, thin lines) since 1 December. Values of the initial contents on 1 December $\left(H C_{\text {init }}, S C_{\text {init }}\right)$, of the final contents at the date of maximum convection, i.e., $10 \mathrm{March}\left(H C_{f i n}, S C_{f i n}\right)$, of the variation of the heat content (Delta HC, Delta SC), of the cumulated surface heat flux (Surf. HC), and of the cumulated lateral atmospheric heat and salt fluxes (Lat. HC and Lat. SC) between 1 December and 10 March are indicated in black.

887 flux and initial salt content over years of deep convection. 888 Between winters 1970-1971 or 1980-1981 and winter 889 2004-2005, the difference of freshwater flux is $\Delta W F_{D J F}=$ $890[0.5 ; 0.8] \mathrm{mm} \mathrm{d}^{-1}$ corresponding a difference of volume of $891 d V=[0.05 ; 0.08] \mathrm{m}$ over a period of 100 days (i.e., approxi892 mately the length of the convection period, beginning of 893 December to mid-March). The mean height of the water 894 column is $\sim 2000 \mathrm{~m}$. The difference of salinity induced by 895 this difference of freshwater flux is therefore $d S_{W F} \sim 38 \times$ $896[0.05 ; 0.08] / 2000=[0.9 ; 1.5] 10^{-3}$. Between winters 1970 8971971 or 1980-1981 and winter 2004-2005, the difference of 898 salt content is $\Delta S C_{01 / 12}=[40 ; 80] 10^{4} \mathrm{~g} \mathrm{~m}^{-2}$. The difference 899 of salinity induced by this difference of salt content is equal $900 d S_{S C} \sim[40 ; 80] 10^{4} /(1029 \times 2000)=[1.9 ; 3.9] 10^{-2}$.

901 [50] In our model, the variation of salinity induced by the 902 interannual variability of freshwater fluxes during the con903 vection period is therefore $\sim 20$ times smaller than the var904 iation of salinity associated to variability of the initial salt 905 content, hence negligible. This justifies that we could 906 neglect the impact of the freshwater flux on the average 907 salinity and therefore relate the salinity of DW directly to the 908 total salt content, and not only to the average salinity.

909 [51] The evolution of the terms of equation (4) are shown 910 in Figure 10. The evolution of the variation of heat content 911 during the convection event is very similar in each simula912 tion, as well as the evolution of the cumulated lateral and 913 surface heat fluxes.As a result, the contribution of those 914 fluxes to the variability of the heat content is 1 order of 915 magnitude smaller than the contribution of the initial heat 916 content: the values of the standard deviation among the si917 mulations of the total cumulated lateral and surface heat 918 fluxes between 1 December and 10 March, when the con919 vection is the strongest, are equal to $510^{7}$ and $310^{7} \mathrm{~J} \mathrm{~m}^{-2}$, 920 respectively, i.e., approximately 10 to 20 times smaller than the standard deviation of the initial heat content $\left(\begin{array}{llll}6 & 10^{8} & \mathrm{~J} & 921\end{array}\right.$ $\mathrm{m}^{-2}$ ). Similarly, the variability of the lateral salt flux, which 922 evolves similarly in each simulation, is much weaker than 923 the variability of the initial salt content: the standard devi- 924 ation of the total cumulated lateral salt flux is equal to $3.7 \mathrm{~kg} 925$ $\mathrm{m}^{-2}$, i.e., $\sim 10$ times smaller than the standard deviation of 926 the initial salt content $\left(35 \mathrm{~kg} \mathrm{~m}^{-2}\right)$.

927

[52] Our results suggest that for given atmospheric con- 928 ditions, the variability of the characteristics of the newly 929 formed WMDW is mainly related to the variability of the 930 initial heat and salt contents. The lateral oceanic heat and 931 salt fluxes during the convection do not contribute signifi- 932 cantly to the variability of these heat and salt contents, hence 933 to the variability of the WMDW characteristics. 934

3.3.2.2. Impact of the Atmospheric Conditions During 935 the 2004-2005 Convection Event on the WMDW 936 Characteristics

937

[53] We showed in section 3.3.1 that the intensity of 938 winter convection in terms of depth is mainly driven by the 939 autumn and winter atmospheric conditions. The deeper the 940 convection is, the larger the amount of WMDW already 941 present in the convection area and mixed with the overlying 942 water is. The relative proportions of WMDW and LIW 943 contributing to the formation of new WMDW are therefore 944 larger and smaller, respectively, when the convection is 945 deeper. For given initial oceanic conditions, the WMDW 946 being less warm and salty than the LIW, the temperature and 947 salinity of the resulting newly formed WMDW will there- 948 fore be smaller for larger depths of convection. This effect 949 can be observed in our modeling study when comparing 950 simulations where initial oceanic conditions are identical 951 and where atmospheric conditions are different but induce 952 deep convection, i.e., year 1970 of CTRL with CI70, year 953 1980 of CTRL with CI80, and AF70, AF80 and year 2004954 
955 of CTRL: for given initial oceanic conditions, $T_{D W}$ and $S_{D W}$ 956 decrease when $M L D_{\max }$ and $M L D_{\text {mean }}$ increase (Table 3). In 957 particular, the comparison of AF70, AF80 and year 2004 of 958 CTRL shows that if different atmospheric conditions had 959 occurred in 2004-2005, e.g., those of winters 1970-1971 or 960 1980-1981, deep convection could still have occurred $961\left(M L D_{\max }=1883 \mathrm{~m}\right.$ in AF70, $2562 \mathrm{~m}$ in AF80 and $2601 \mathrm{~m}$ 962 in CTRL) and the change of WMDW could have been even 963 more spectacular than the change observed in reality since 964 the mixed layer would have been slightly shallower $\left(T_{D W}\right.$ 965 and $S_{D W}$ are equal to $13.04^{\circ} \mathrm{C}$ and 38.513 in $\mathrm{AF} 70$ and $96612.92^{\circ} \mathrm{C}, 38.488$ in $\mathrm{AF} 80$ versus $12.90^{\circ} \mathrm{C}, 38.483$ in CTRL). 967 Another interesting point is that the characteristics of con968 vection during winter $1980-1981$ of CTRL $\left(12.90^{\circ} \mathrm{C}\right.$, 96938.479 and $29.113 \mathrm{~kg} \mathrm{~m}^{-3}$ ) correspond to new character970 istics: the conjunction of smaller heat and salt contents than 971 those of August $2004\left(1.18810^{11} \mathrm{~J} \mathrm{~m}^{-2}\right.$ and $8.73310^{4} \mathrm{~kg}$ $972 \mathrm{~m}^{-2}$ in $1980-1981$ versus $1.19810^{11} \mathrm{~J} \mathrm{~m}^{-2}$ and $8.73710^{4} \mathrm{~kg}$ $973 \mathrm{~m}^{-2}$ in 2004-2005; Figure 4 and Table 3) with smaller 974 maximum and mean MLD (2382 $\mathrm{m}$ and $510 \mathrm{~m}$ versus 2601 $975 \mathrm{~m}$ and $943 \mathrm{~m}$; Table 3 ) led to the formation of WMDW with 976 similar characteristics $\left(12.90^{\circ} \mathrm{C}, 38.479\right.$ versus $12.90^{\circ} \mathrm{C}$, 977 38.483). Finally the atmospheric conditions during the 978 convection indirectly influence the characteristics of newly 979 formed WMDW by determining the depth of convection.

980 3.3.2.3. Impact of the EMT on WMDW Characteristics 981 [54] Finally, the results obtained in sections 3.3.2.2 and 982 3.3.2.1 show that the change of temperature and salinity of 983 the WMDW formed during winter 2004-2005 compared to 984 the WMDW formed before was not due to the atmospheric 985 conditions neither to the lateral oceanic advection during 986 this winter, but to the initial heat and salt contents of autumn 9872004 over LION, which were exceptionally high. We 988 showed in section 3.1 that these high 2004 contents, ob989 tained both in NEMT and CTRL, were not due to the EMT 990 but to the absence of deep convection during the 1990s, 991 itself induced by a succession of weak buoyancy loss win992 ters. Our results therefore show that the EMT was not 993 responsible for the change of WMDW characteristics 994 observed during the 2005 convection episode, contrary to 995 what was suggested by Schroeder et al. [2008].

996 [55] Note that this result explains why the simulation used 997 by Herrmann et al. [2009] in order to study the interannual 998 variability of the NWMED convection for the period 1998 9992007 was not able to reproduce the change of WMDW 1000 characteristics observed in 2005. During the 10 years spin-up 1001 corresponding to the period 1987-1997, ERA40 fields were 1002 indeed used for the atmospheric forcing. Their resolution, $1003 \sim 125 \mathrm{~km}$, is not sufficient to reproduce realistically the 1004 Mediterranean circulation and in particular the NWMED 1005 deep convection [Herrmann and Somot, 2008]. Conse1006 quently, this simulation could not reproduce correctly the 1007 circulation of water masses during this period in the 1008 NWMED, and therefore the salting and warming responsible 1009 for the change of WMDW characteristics observed in 2005.

\section{4. Conclusion}

1011 [56] In this paper we focus on the exceptionally strong 1012 convection event that occurred in the NWMED during winter 1013 2004-2005, associated with newly formed WMDW warmer 1014 and saltier than usually. Experimental oceanographers that observed this event proposed two explanations: the first one 1015 relates the exceptional intensity of this convection event, as 1016 well as the change of the characteristics of WMDW formed 1017 this winter to the atmospheric conditions. The second one 1018 relates them to the effect of the EMT on the intermediate 1019 layer of the NWMED, hence on the oceanic conditions. We 1020 used numerical modeling in order to determine which ele- 1021 ment played a role in this event, and how.

1022

[57] We first performed a realistic numerical simulation of 1023 the Mediterranean oceanic circulation during the 1960-2006 1024 period. The long-term analysis of this simulation was per- 1025 formed by Beuvier et al. [2010], who validated the long- 1026 term evolution of the temperature and salinity in the whole 1027 basin, and showed that the model reproduces correctly the 1028 EMT. Here we showed that this control simulation is able to 1029 reproduce realistically the 2005 NWMED convection event: 1030 the temporal and spatial evolution of the convection event as 1031 well as the WMDW characteristics were consistent with 1032 satellite and in situ observations.

[58] Sensitivity simulations then allowed us to assess the 1034 respective contributions of the oceanic and atmospheric 1035 conditions to the 2004-2005 convection event. First, we 1036 examined the factors that led to the structure of the water 1037 column in the NWMED just before the convection. Our model 1038 suggests that a succession of winters of weak atmospheric 1039 buoyancy loss was responsible for the absence of deep con- 1040 vection during the 1990s. This would have enabled the heat 1041 and salt to accumulate in the intermediate layer. Conse- 1042 quently, the heat and salt contents of autumn 2004 were the 1043 highest of the whole 1960-2005 period, in agreement with the 1044 observations of Schroeder et al. [2010]. According to our 1045 model, the EMT did not contribute significantly to this 1046 warming and salting of the intermediate layer, but it induced 1047 the deepening of the heat and salt maximum in the NWMED. 1048 This deepening, already observed by Gasparini et al. [2005], 1049 was associated with a weakening of the stratification of the 1050 water column in autumn 2004 compared to what would have 1051 been the case without the EMT.

[59] We then determined which were the key factors that 1053 could be responsible for the characteristics of the 2004- 1054 2005 convection event. In our model, the abrupt change of 1055 WMDW characteristics observed in 2005 predominantly 1056 resulted from the high heat and salt contents of autumn 1057 2004. It therefore seems that it was not due do the EMT but 1058 to the weakness of the winter atmospheric buoyancy loss 1059 and deep convection in the NWMED during the 1990s. 1060 Moreover, our results suggest that the lateral oceanic heat 1061 and salt fluxes during winter 2004-2005 did not play a 1062 significant role in the settings of the WMDW characteristics. 1063 The atmospheric conditions of 2004-2005, namely the 1064 strong autumn and winter atmospheric buoyancy losses, 1065 mainly drove the deepening of the mixed layer in our model. 1066 They consequently appear to be the major factor responsible 1067 for the exceptional intensity of the convection observed this 1068 winter in terms of depth and volume of newly formed 1069 WMDW. The EMT would have accentuated the effect of the 1070 atmospheric forcing by weakening the stratification, hence 1071 facilitating the vertical mixing of the water column. This 1072 would have not fundamentally change the convection pro- 1073 cess and depth but potentially doubled the volume of newly 1074 formed WMDW. Finally, our conclusions were obtained 1075 using a given ocean model forced by a given atmospheric 1076 
1077 data set. It would be necessary to perform other simulations 1078 using other models and atmospheric forcings in order 1079 enforce the robustness of our conclusions or to propose 1080 alternative explanations.

1081 [60] In this study, we focused on winter 2004-2005 and 1082 on the NWMED in order to understand the mechanisms 1083 responsible for the spectacular convection that occurred this 1084 year. WMDW formed in 2005 then propagated into the rest 1085 of the basin [Schroeder et al., 2008] and a signal apparently 1086 reached the Gibraltar Strait. García Lafuente et al. [2007] 1087 indeed observed a decrease of the temperature of the Med1088 iterranean Outflow Water in March 2005 and 2006. They 1089 attributed it to a remote signature of the strong NWMED 1090 convection that occurred those winters. Our simulations 1091 could help to understand how the 2004-2005 convection 1092 event in the NWMED influenced the circulation in the rest 1093 of the basin and this motivates further studies. Our next goal 1094 is to use and perform additional realistic long-term simu1095 lations in order to quantify more generally the contributions 1096 of the oceanic and atmospheric conditions to the interannual 1097 variability of the convection characteristics, in the NWMED 1098 but also in the other regions of deep and intermediate con1099 vection of the Mediterranean Sea (Adriatic, Aegean, 1100 Levantine subbasins) and study how these local processes 1101 can interact between each other in particular through the 1102 thermohaline circulation.

1103 [61] Acknowledgments. This study has been sponsored by the 1104 "Forecast and projection in climate scenario of Mediterranean intense 1105 events: Uncertainties and Propagation on environment" (MEDUP) project 1106 of the program Vulnérabilité: Milieux et Climat from the Agence Nationale

1107 pour la Recherche and by the HyMeX project (Hydrological cycle in 1108 the Mediterranean experiment (www.hymex.org)). We thank C. Millot, $1109 \mathrm{~K}$. Schroeder, and an anonymous reviewer for their comments and sugges1110 tions that helped to improve the quality of this paper. We also thank 1111 D. Quoc-Phi, M. Remaud, and A. Verrelle for their work at the very begin1112 ning of this study.

\section{References}

1114 Barnier, B., et al. (2006), Impact of partial steps and momentum advection

1115 schemes in a global ocean circulation model at eddy-permitting resolu-

1116 tion, Ocean Dyn., 56, 543-567.

1117 Beuvier, J., F. Sevault, M. Herrmann, H. Kontoyiannis, W. Ludwig,

1118 M. Rixen, E. Stanev, K. Béranger, and S. Somot (2010), Modeling the

1119 Mediterranean Sea interannual variability during 1961-2000: Focus on

1120 the Eastern Mediterranean Transient (EMT), J. Geophys. Res., 115, 1121 C08017, doi:10.1029/2009JC005950.

1122 Blanke, B., and P. Delecluse (1993), Nariability of the tropical Atlantic

1123 Ocean simulated by a general circulation model with two different mixed 1124 layer physics, J. Phys. Oceanogr., 23, 1363-1388.

1125 Bozec, A., P. Bouret-Aubertot, D. Iudicone, and M. Crépon (2008), Impact

1126 of penetrative solar radiation on the diagnosis of water mass transforma-

1127 tion in the Mediterranean Sea, J. Geophys. Res., 113, C06012,

1128 doi:10.1029/2007JC004606.

1129 Castellari, S., N. Pinardi, and K. Leaman (2000), Simulation of water mass

1130 formation processes in the Mediterranean Sea: Influence of the time

1131 frequency of the atmospheric forcing, J. Geophys. Res., 105(C10),

1132 24,157-24,181, doi:10.1029/2000JC900055.

1133 CLIPPER Project Team (1999), Modélisation à haute résolution de la cir-

1134 culation dans l'océan Atlantique forcée et couplée océan-atmosphère,

1135 Sci. Tech. Rep. CLIPPER-R3-99, Lab. des Ecoulements Géophys. et

1136 Ind., Grenoble, France.

1137 Déqué, M., and J. Piedelievre (1995), High-resolution climate simulation 1138 over Europe, Clim. Dyn., 11, 321-339.

1139 Font, J., P. Puig, J. Salat, A. Palanques, and M. Emelianov (2007),

1140 Sequence of hydrographic changes in NW Mediterranean deep water 1141 due to the exceptional winter of 2005, Sci. Mar., 71, 339-346.

1142 García Lafuente, J., A. Sánchez Román, G. Díaz del Río, G. Sannino, and

1143 J. C. Sánchez Garrido (2007), Recent observations of seasonal variability of the Mediterranean outflow in the Strait of Gibraltar, J. Geophys. Res., 1144 112, C10005, doi:10.1029/2006JC003992. 1145

Gasparini, G., A. Ortona, G. Budillon, M. Astraldi, and E. Sansone (2005), 1146 The effect of the Eastern Mediterranean Transient on the hydrographic 1147 characteristics in the Strait of Sicily and in the Tyrrhenian Sea, Deep 1148 Sea Res., Part II, 52, 915-935.

1149

Gibson, J., P. Kållberg, S. Uppala, A. Hernandez, and E. Serano (1997), 1150 ERA description, in Re-anal, Proj. Rep. Ser., Eur. Cent. for Medium- 1151 Range Weather Forecast, Reading, U. K. 1152

Guldberg, A., E. Kaas, M. Déqué, S. Yang, and S. Vester Thorsen (2005), 1153 Reduction of systematic errors by empirical model correction: Impact on 1154 seasonal prediction skill, Tellus, Ser. A, 57, 575-588.

Herrmann, M. J., and S. Somot (2008), Relevance of ERA40 dynamical 1156 downscaling for modeling deep convection in the Mediterranean Sea, 1157 Geophys. Res. Lett., 35, L04607, doi:10.1029/2007GL032442. 1158

Herrmann, M., S. Somot, F. Sevault, C. Estournel, and M. Déqué (2008), 1159 Modeling the deep convection in the northwestern Mediterranean sea 1160 using an eddy-permitting and an eddy-resolving model: Case study of 1161 winter 1986-1987, J. Geophys. Res., 113, C04011, doi:10.1029/ 1162 2006JC003991. 1163

Herrmann, M., J. Bouffard, and K. Béranger (2009), Monitoring open- 1164 ocean deep convection from space, Geophys. Res, Lett., 36, L03606, 1165 doi:10.1029/2008GL036422. 1166

Kalnay, E., et al. (1996), The NCEP/NCAR 40-year reanalysis project, 1167 Bull. Am. Meteorol. Soc., 77, 437-471. 1168

López-Jurado, J.-L., C. González-Pola, and P. Vélez-Belchí (2005), Obser- 1169 vation of an abrupt disruption of the long-term warming trend at the 1170 Balearic Sea, western Mediterranean Sea, in summer 2005, Geophys. 1171 Res. Lett., 32, L24606, doi:10.1029/2005GRL024430. 1172

Madec, G. (2008), NEMO ocean engine, Note Pole de Modélisation 27, 1173 Inst. Pierre-Simon Laplace, Paris.

Marshall, J., and F. Schott (1999), Open-ocean convection: Observations, 1175 theory, and models, Rev. Geophys., 37(1), 1-64. 1176

MEDAR/MEDATLAS Group (2002), MEDAR/MEDATLAS 2002 Data- 1177 base: Cruise Inventory, Observed and Analysed Data of Temperature 1178 and Bio-Chemical Parameters [4 CD-ROMs], Inst. Fr. de Rech. Pour 1179 1'Exploit. de la Mer, Brest, France.

Mertens, C, and F. Schott (1998), Interannual variability of deep-water 1181 formation in the northwestern Mediterranean, J. Phys. Oceanogr., 28, 1182 1410-1424.

Millot, C. (1999), Circulation in the western Mediterranean Sea, J. Mar. 1184 Syst., 20, 423-442. 1185

Millot, C. (2005), Circulation in the Mediterranean Sea: Evidences, debates 1186 and unanswered questions, Sci. Mar., 69 5-21, doi:10.3989/scimar. 1187 2005.69s15. 1188

Perry, K. (2001), SeaWinds on QuikSCAT Level 3 Daily, Gridded Ocean 1189 Wind Vectors (JPL SeaWinds Project), http://podaac.jpl.nasa.gov/ 1190 DATA_CATALOG/quikscatinfo.html, JPL Phys. Oceanogr. DAAC, 1191 Pasadena, Calif.

Reynaud, T., P. Legrand, H. Mercier, and B. Barnier (1998), A new anal- 1193 ysis of hydrographic data in the Atlantic and its application to an inverse 1194 modeling study, Int. World Ocean Circ. Exp. Newsl. 32, Natl. Oceanogr. 1195 Data Cent., Silver Spring, Md. 1196

Rixen, M., et al. (2005), The Eestern Mediterranean Deep Water: A proxy 1197 for climat change, Geophys. Res. Lett., 32, L12608, doi:10.1029/ 1198 2005GL022702.

1199

Roether, W., B. Klein, B. Manca, A. Theocharis, and S. Kioroglou (2007), 1200 Transient eastern Mediterranean deep waters in response to the massive 1201 dense-water output of the Aegean Sea in the 1990s, Prog. Oceanogr., 74, 1202 540-571.

Salat, J., M. Emelianov, and J. López-Jurado (2006), Unusual extension of 1204 western Mediterranean deep water formation during winter 2005, paper 1205 presented at 5 Asamblea Hispano-Portuguesa de Geodesia y Geofísica, 1206 Minist. de Medio Ambiente, Sevilla, Spain. 1207

Sannino, G., M. Herrmann, A. Carillo, V. Rupolo, V. Ruggiero, V. Artale, 1208 and P. Heimbach (2009), An eddy-permitting model of the Mediterra- 1209 nean Sea with a two-way grid refinement at the Strait of Gibraltar, Ocean 1210 Modell., 30, 56-72, doi:10.1016/j.ocemod.2009.06.002. 1211

Schröder, K., G. P. Gasparini, M. Tangherlini, and M. Astraldi (2006), 1212 Deep and intermediate water in the western Mediterranean under the 1213 influence of the Eastern Mediterranean Transient, Geophys. Res. Lett., 1214 33, L21607, doi:10.1029/2006GL027121.

1215

Schroeder, K., A. Ribotti, M. Borghini, R. Sorgente, A. Perilli, and 1216 G. P. Gasparini (2008), An extensive Western Mediterranean Deep 1217 Water renewal between 2004 and 2006, Geophys. Res. Lett., 35, 1218 L18605, doi:10.1029/2008GL035146.

1219

Schroeder, K., S. A. Josey, M. Herrmann, L. Grignon, G. P. Gasparini, and 1220 H. L. Bryden (2010), Abrupt warming and salting of the Western Med- 1221 
1222 iterranean Deep Water: Atmospheric forcings and lateral advection, 1223 J. Geophys. Res., 115, C08029, doi:10.1029/2009JC005749.

1224 Sevault, F., S. Somot, and J. Beuvier (2009), A regional version of the guide, Note Cent. 107, Groupe de Météorol. de Grande Echelle et Climat, CNRM, Toulouse, France.

mith, R. O., H. L. Bryden, and K. Stansfield (2008), Observations of new Western Mediterranean Deep Water formation using Argo floats 20042006, Ocean Sci., 4, 133-149.

Smith, W., and D. Sandwell (1997), Global sea floor topography from satellite altimetry and ship depth sounding, Science, 277(5334), 1956-1962. Somot, S., F. Sevault, and M. Déqué (2006), Transient climate change scenario simulation of the Mediterranean Sea for the twenty-first century using a high-resolution ocean circulation model, Clim. Dyn., 27, 851579, doi:10.1007/s00382-006-0167-z.
Stanev, E., P.-Y. Le Traon, and E. Peneva (2000), Sea level variations and 1237 their dependency on meteorological and hydrological forcing: Analysis 1238 of altimeter and surface data for the Black Sea, J. Geophys. Res., 1239 105(C7), 17,203-17,216. . 1242 orosmarty, C., B. Fekete, and B. Tucker (1996), Global River Discharge 1243 Database (RivDis), Int. Hydrol. Program, Global Hydrol. Archive and 1244 Anal. Syst., UNESCO, Paris.

J. Beuvier, ENSTA-ParisTech/UME, Chemin de la Hunière, F-91761 1246 Palaiseau CEDEX, France.

M. Herrmann, F. Sevault, and S. Somot, CNRM-GAME, Météo-France, 1248 42 Ave. Gaspard Coriolis, F-31057 Toulouse CEDEX, France. (marine. 1249 herrmann@m4x.org)
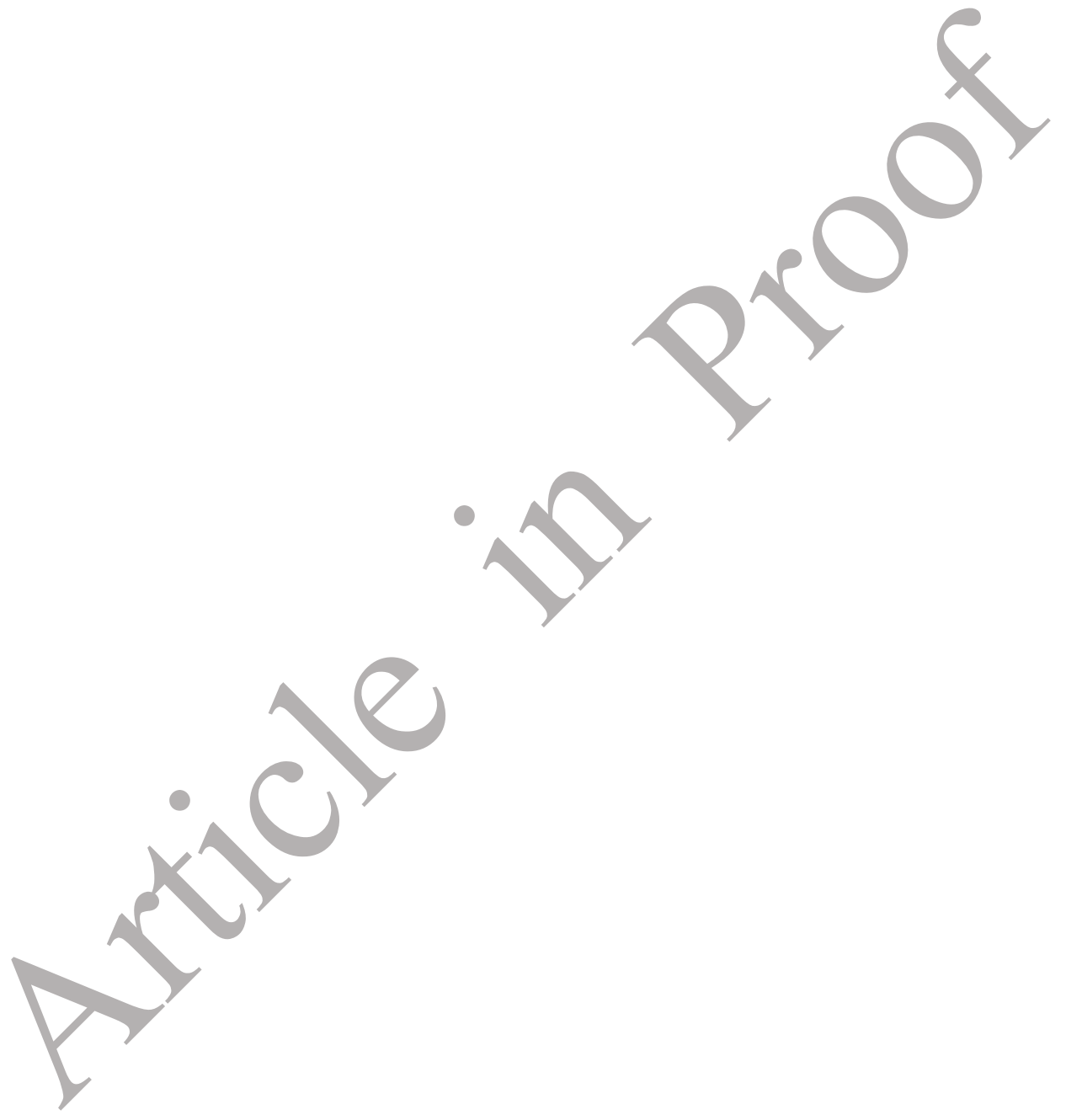